\title{
Poly-L-lysine Functionalized Large Pore Cubic Mesostructured Silica Nanoparticles as Biocompatible Carriers for Gene Delivery
}

\author{
Sandy B. Hartono, ${ }^{\dagger, \#}$ Wenyi Gu, ${ }^{\dagger, \#}$ Freddy Kleitz, ${ }^{\S}$ Jian Liu, ${ }^{\dagger}$ Lizhong He, ${ }^{\perp, *}$ Anton P. J. Middelberg, ${ }^{\perp}$ \\ Chengzhong Yu, ${ }^{\dagger}{ }^{+*}$ Gao Qing (Max) Lu, ${ }^{\dagger}$ and Shi Zhang Qiao ${ }^{\dagger, \neq, *}$ \\ ${ }^{\dagger}$ ARC Centre of Excellence for Functional Nanomaterials, Australian Institute for Bioengineering and Nanotechnology, The University of Queensland, QLD 4072, \\ Australia, ${ }^{\ddagger}$ School of Chemical Engineering, The University of Adelaide, SA5005, Australia, ${ }^{5}$ Department of Chemistry and Centre de Recherche sur les Matériaux \\ Avancés (CERMA), Université Laval, Quebec City, G1 V OA6, QC, Canada, and ${ }^{\perp}$ Centre for Biomolecular Engineering, Australian Institute for Bioengineering and \\ Nanotechnology, The University of Queensland, QLD 4072, Australia. "These authors contributed equally to this work.
}

S iRNA-based therapeutics have great potential to suppress pathogenic gene expressions. ${ }^{1,2}$ Gene therapy can be applied for various disease treatments such as cancer, neurodegenerative diseases, antiviral diseases, hematological diseases and hereditary genetic disorders. ${ }^{3}$ However, progress of siRNA cancer therapy relies on the development of safe and effective delivery systems. The usage of novel nanocarriers offers substantial advantages including the prevention of degradation, possibility of delivering high concentrations of siRNA into tumor tissues, specific targeting, and controlled release. ${ }^{1}$

The development of novel nanocarriers capable of delivering drugs to the organism in an efficient manner has attracted much attention. Polymer- and liposome-based nanoparticles are nowadays among the most commonly used materials for gene delivery. ${ }^{1,3,4}$ Recently, however, silica-based materials have emerged as new candidates for targeted drug delivery applications, 5,6 which can offer distinct advantages over other materials. Silica is usually less toxic compared to polycations. ${ }^{7}$ Porous silica materials have shown substantial benefits in terms of loading owing to their high porosity (i.e., high surface area and high pore volume), tunable pore size in the nanometer regime, and vast surface functionalization capabilities. $^{8,9}$

Previous studies in this area have shown the effectiveness of silica-based materials to transfer genes and anticancer drugs into target cells. In particular, nanosized silica particles (nonporous) were used for
ABSTRACT Large pore mesoporous silica nanoparticles (LP-MSNs) functionalized with polyL-lysine (PLL) were designed as a new carrier material for gene delivery applications. The synthesized LP-MSNs are $100-200 \mathrm{~nm}$ in dia-

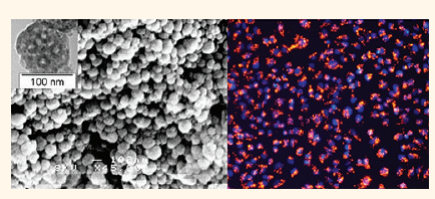
meter and are composed of cage-like pores organized in a cubic mesostructure. The size of the cavities is about $28 \mathrm{~nm}$ with an entrance size of $13.4 \mathrm{~nm}$. Successful grafting of PLL onto the silica surface through covalent immobilization was confirmed by $X$-ray photoelectron spectroscopy, solid-state ${ }^{13} \mathrm{C}$ magic-angle spinning nuclear magnetic resonance, Fourier transformed infrared, and thermogravimetric analysis. As a result of the particle modification with PLL, a significant increase of the nanoparticle binding capacity for oligo-DNAs was observed compared to the native unmodified silica particles. Consequently, PLL-functionalized nanoparticles exhibited a strong ability to deliver oligo DNA-Cy3 (a model for siRNA) to Hela cells. Furthermore, PLL-functionalized nanoparticles were proven to be superior as gene carriers compared to amino-functionalized nanoparticles and the native nanoparticles. The system was tested to deliver functional siRNA against minibrain-related kinase and polo-like kinase 1 in osteosarcoma cancer cells. Here, the functionalized particles demonstrated great potential for efficient gene transfer into cancer cells as a decrease of the cellular viability of the osteosarcoma cancer cells was induced. Moreover, the PLL-modified silica nanoparticles also exhibit a high biocompatibility, with low cytotoxicity observed up to $100 \mu \mathrm{g} / \mathrm{mL}$.

KEYWORDS: mesoporous silica nanoparticles $\cdot$ poly-L-lysine $\cdot$ gene delivery . siRNA · cellular uptake

the first time as inorganic nonviral gene delivery carriers by Kneuer et al. in 2000. ${ }^{10}$ Silica nanoparticles with different sizes (10-100 $\mathrm{nm}$ ) were modified with aminosilanes to generate positive charges around the surface, and the resulting materials were able to condense and protect plasmid DNA. ${ }^{10}$ The major advantage of using porous silica materials compared to nonporous ones is the possibility to bind biomolecules either on the surface or within the pore and

\author{
*Address correspondence to \\ s.qiao@uq.edu.au \\ c.yu@uq.edu.au, \\ I.he@uq.edu.au.
}

Received for review October 14, 2011 and accepted March 2, 2012.

Published online March 02, 2012 $10.1021 / \mathrm{nn} 2039643$

(C) 2012 American Chemical Society 
achieve much higher loadings, ${ }^{7}$ with potential for codelivery. ${ }^{11}$ Thus far, mesoporous silica materials with small pore size $(<3 \mathrm{~nm})$ were reported as potential carriers to deliver siRNA ${ }^{7,11,12}$ and DNA. ${ }^{7}$ In these approaches, due to the small pore size, the genes remain coated only on the external surface of the mesoporous silica materials. Recently, Li et al. showed that large amount of double stranded salmon DNA (20-250 bp with an average chain length of $50 \mathrm{~nm}$ ) could be adsorbed within the pore $(2.7 \mathrm{~nm})$ of magnetic mesoporous silica nanoparticles by optimizing adsorption conditions. ${ }^{13}$

The importance of pore size of mesoporous silica materials in gene adsorption was first discussed by Solberg et al. ${ }^{14}$ They proved that DNA adsorption was dependent on the pore size. Subsequently, Gao et al. used large pore $(\sim 20 \mathrm{~nm})$ mesoporous silica nanoparticles $(70-300 \mathrm{~nm})$ to adsorb large plasmid DNA (5256 bp). ${ }^{15}$ These authors achieved very high amounts of adsorbed pDNA (9.7 $\mu \mathrm{g} / \mathrm{mg})$. Most of the pDNA was adsorbed inside the mesopores, confirming the importance of larger pore size to increase adsorption. Similarly, Kim et al. showed the benefit of using large pore mesoporous silica as a DNA carrier in order to achieve high plasmid DNA loadings and enhanced protection of DNA against DNase degradation. ${ }^{16}$ This study confirmed that large pore mesoporous silica materials were indeed more effective gene delivery carriers as compared to the small pore counterparts. In addition, mesoporous silicon microsize particles with large pore size have also been used to produce sustained siRNA delivery. The large pores were used to adsorb siRNA-liposomes complex. ${ }^{17}$ However, submicrometer size materials (nanoparticles) are clearly preferred compared to the micrometer size particles. First, micrometer size particles (larger than $200 \mathrm{~nm}$ ) are cleared faster from blood circulation. ${ }^{15,18}$ Second, nanosize particles lead to higher cellular uptake compared to the micrometer size particles. ${ }^{4,16}$

From these results, we see the potency of using large pore mesoporous silica nanoparticles (LP-MSNs) as carriers for siRNA delivery. However, the successful application of LP-MSNs for delivery of nucleic acidbased drugs requires surface modification of the silica in order to generate sufficient binding affinity for the negatively charged nucleic acids. Various techniques have been implemented to place positively charged functional groups in silica materials, either through noncovalent interactions or by covalent bonding. Amino-silanes and polycation polymers have been widely used as chemical agents to modify the silica surfaces. ${ }^{7,10,11,19}$ Especially, PLL is one of the first polycations that were used as carriers for gene delivery. ${ }^{20}$ Although PLL alone can effectively deliver genes into target cells, ${ }^{21}$ a combination with mesoporous silica could offer supplementary advantages. ${ }^{11,19,22}$
Li et al. used electrostatic interactions to form a complex of PLL and silica nanoparticles ${ }^{23-25}$ and applied this system as a vehicle for plasmid DNA delivery. ${ }^{23}$ They showed that such a complex could efficiently bind genes and protect them from enzymatic degradation, and, consequently, deliver antisense oligonucleotides (ODNs) selectively into cells. ${ }^{24}$ However, simple adsorption of PLL could not be used to uniformly modify silica particles larger than $60 \mathrm{~nm}$, possibly due to the unfavorable surface energy of large silica particles. ${ }^{23}$ Lunn et al. ${ }^{26}$ used surface-initiated polymerization of $\mathrm{N}$-carboxyanhydrides (NCAs) to graft peptide (PLL and poly-L-alanine) on the surface of amine-functionalized mesoporous silica materials (MCM-41, SBA-15, and KIT-6). However, this functionalization procedure resulted in significant reduction of the porosity of the silica particles and pore blockage at high peptide loading. Consequently, the loading capacity of the particles was dramatically decreased. Differently, Kar et al. ${ }^{27}$ reported the use of a "grafting to" approach by combining NCA polymerization and click chemistry to synthesize PLL-grafted SBA-15. This method enables the grafting with precise molecular weights and maintains the materials porosity. Yet, this approach remains time-consuming in order to accomplish the multistep synthesis procedure.

In this work, we develop a novel and facile method to attach PLL onto LP-MSNs to produce LP-MSN-P (poly-L-lysine functionalized large pore mesoporous silica nanoparticles) and use it as a carrier to deliver siRNA into cancer cells. We first prepared LP-MSNs as the hosts which were subsequently functionalized by grafting of epoxysilane (3-glycidoxypropyl trimethoxysilane (3-GPS)) to yield LP-MSN-E, and then LP-MSN-P. Amine (APTES) functionalized LP-MSNs (LP-MSN-A) were also synthesized for comparison. The influences of the different surface functionalization (PLL, amine, and unfunctionalized) on DNA adsorption, cell uptake, cytotoxicity and biological function are then substantiated. It was found that LP-MSN-P has much higher affinity for nucleic acids than unfunctionalized LP-MSNs. LP-MSN-P is proved to be far more efficient in supporting cancer cells transfection as compared to the LP-MSN-A and unfunctionalized silica nanoparticles. At a low concentration ( $<100 \mu \mathrm{g} / \mathrm{mL}$ ), LP-MSN-P has low cytotoxicity. Moreover, we also demonstrate that the LP-MSN-P can effectively deliver siRNA into cancer cells and silence the oncogenes.

\section{RESULTS AND DISCUSSION}

Synthesis of Large Pore Mesoporous Silica Nanoparticles (LP-MSNs). LP-MSNs with a 3-D cubic mesostructure were synthesized following a method previously reported. ${ }^{15}$ These nanoparticles are expected to be promising for drug and gene delivery, because a cubic pore network with a high degree of pore interconnectivity allows 


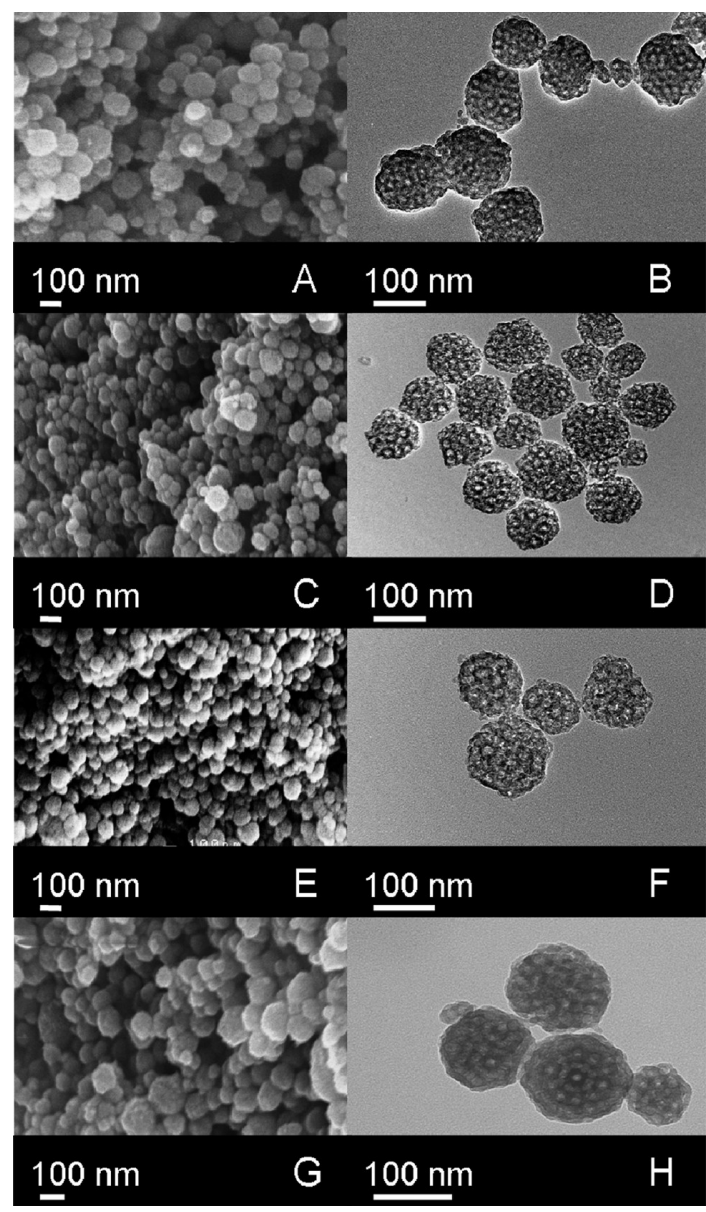

Figure 1. SEM images of (A) LP-MSNs, (C) LP-MSN-E, (E) LP-MSN-P, and (G) LP-MSN-A and TEM images of (B) LP-MSNs, and (D) LP-MSN-E, (F) LP-MSN-P, and (H) LP-MSN-A.

superior mass transfer compared to one-dimensional channel-like structures and are more resistant to pore blocking. ${ }^{9,28}$ The synthesis strategy for the LP-MSNs lies on using a dual surfactant system, that is, a combination of triblock copolymer (F127), acting as the cubic pore structure-directing agent, and a fluorocarbon surfactant (FC-4) to control particle growth. Images of the thus-obtained LP-MSNs are shown in Figure 1. The scanning electron microscopy (SEM) images of LP-MSNs shown in Figure $1 \mathrm{~A}$ confirm the formation of spherical particles with a fairly narrow particle size distribution in the range of $100-200 \mathrm{~nm}$. The transmission electron microscopy (TEM) image (Figure 1B) indicates the presence of large pores (around $20 \mathrm{~nm}$ ) with cage-like structure organized in a typical cubic mesostructure in each of the particles. The specific use of FC-4 permits a fine control of the formation of MSNs in order to achieve the desired particle size $(<200 \mathrm{~nm})$. Conversely, the absence of FC-4 causes the production of mesoporous silica with micrometer size particles $(8-12 \mu \mathrm{m})$ as it is the case for standard FDU-12-type materials. ${ }^{9,29}$

Nitrogen physisorption results of the sample LP-MSNs (Supporting Information, Figure S1) demonstrate
TABLE 1. Physicochemical Properties of the Native LP-MSNs and Functionalized Materials

pore size $(\mathrm{nm})$

sample BET $\left(\mathrm{m}^{2} / \mathrm{g}\right)$ pore volume $(\mathrm{mL} / \mathrm{g})$ cavity entrance zeta potential $(\mathrm{mV})$

\begin{tabular}{llllll}
\hline LP-MSNs & 313 & 1.09 & 27.9 & 13.4 & -17.3 \\
LP-MSN-A & 155 & 0.63 & 24.6 & 11.3 & +3.23 \\
LP-MSN-P & 171 & 0.64 & 24.1 & 11.8 & +1.90 \\
\hline
\end{tabular}

a type IV isotherm with $\mathrm{H} 2$ hysteresis loop at high relative pressures indicating the existence of large mesopores with cage-like structures. ${ }^{29}$ The pore size was determined using the Broekhoff-de Boer (BdB) method ${ }^{30}$ considering spherical shape pores, although deviation from ideal spherical pore morphology is possible here. The cavity size of LP-MSNs was evaluated to be $27.9 \mathrm{~nm}$, and the entrance pore size was $13.4 \mathrm{~nm}$. The BET surface area of the samples was $313 \mathrm{~m}^{2} / \mathrm{g}$, and the pore volume was around $1.09 \mathrm{~cm}^{3} / \mathrm{g}$ (Table 1). These data are in line with the results from TEM analysis. The formation of an extra large cavity size and large entrance size is attributed to the use of a low temperature synthesis method $\left(10^{\circ} \mathrm{C}\right)$ followed by relatively high hydrothermal temperatures $\left(140{ }^{\circ} \mathrm{C}\right)$. It is believed that the usage of low temperature enhances the penetration of the swelling agent TMB $(1,3,5-$ trimethylbenzene) into the hydrophobic core of the micelles during synthesis, which ultimately results in an extra enlargement of pore size $(27.9 \mathrm{~nm}){ }^{15,29,31}$ The use of high hydrothermal treatment temperature of $140{ }^{\circ} \mathrm{C}$ contributed in the widening of the entrance pore size above $13.4 \mathrm{~nm}$.

Owing to the small spherical particle size and the large pore size (large unit cell), the mesostructure symmetry of the sample is difficult to determine by powder X-ray analysis (XRD). ${ }^{15,32-34}$ The small particle size of LP-MSNs $(<200 \mathrm{~nm})$ with large pore size $(\sim 28 \mathrm{~nm})$ only allows a small number of unit cells in each single particle (i.e., the size of coherent scattering domains is small). Because of the limited size of ordered pore domains, small-angle X-ray scattering (SAXS) analysis of LP-MSNs shows only one resolved peak (Supporting Information, Figure S2), in agreement with other reports on mesoporous nanoparticles. $^{15,35}$ Nevertheless, TEM investigations confirmed the existence of typical cubic mesostructure in LP-MSNs.

Functionalization of LP-MSNs with PLL (LP-MSN-P) and APTES (LP-MSN-A). The surface modification of mesoporous silica is an essential requirement for the material to be used as a delivery vehicle to transfer genes (DNA/ siRNA) into targeted cells. A selective surface functionalization can introduce positive charges on the silica surface, which in turn permits electrostatic interactions with negatively charged DNA/siRNA. One of the methods to achieve this is to coat the silica with polycation species such as PLL. The above synthesized LP-MSNs 

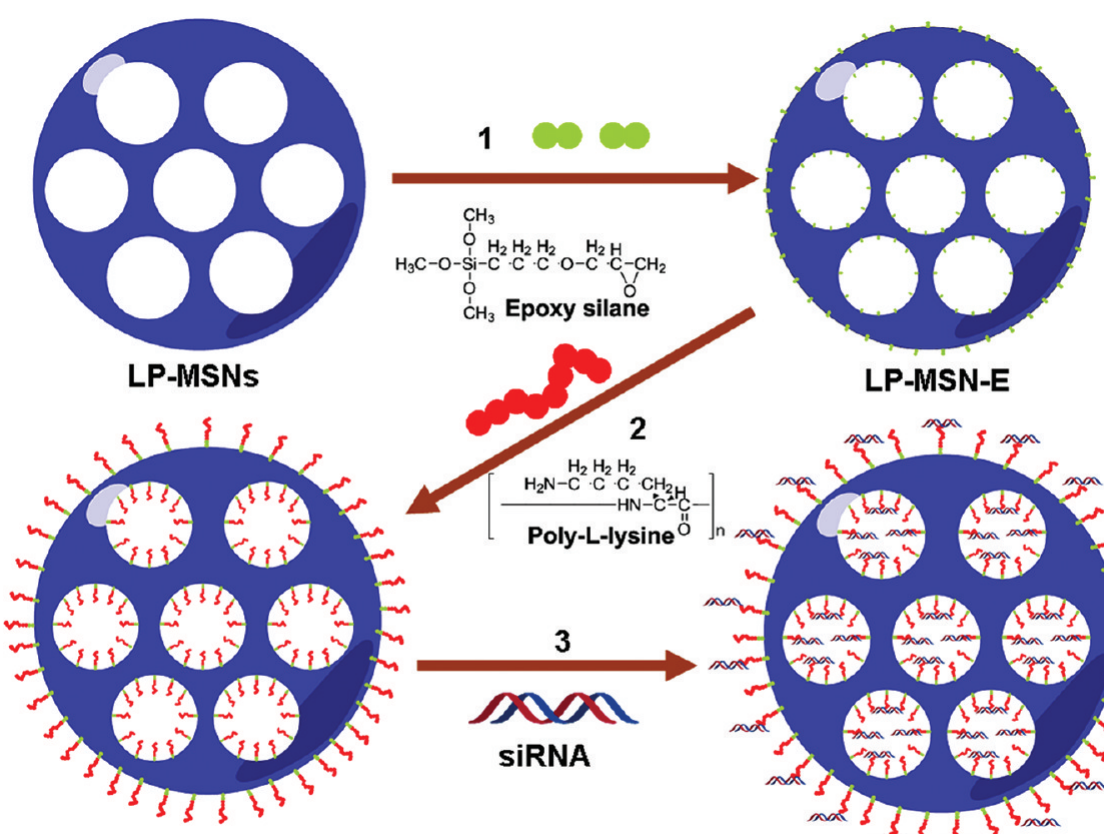

LP-MSN-P

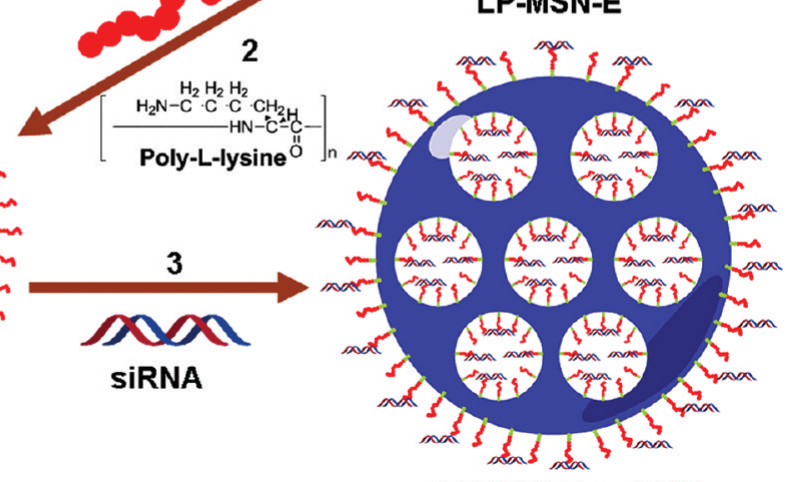

LP-MSN-P + SIRNA

Scheme 1. Schematic Illustration of the Steps for the Poly-L-lysine Grafting and Gene Loading into LP-MSN-P

were modified with PLL and APTES to produce the materials labeled as LP-MSN-P and LP-MSN-A, respectively. This study aims also at comparing the effectiveness of PLL and amine functionalization, as both of them are the most common functional groups to be used in gene carrier surface modification. ${ }^{10,23-25,36}$

The procedure employed for the functionalization of LP-MSNs with PLL is illustrated in Scheme 1. First, (1) 3-GPS was anchored to the silica surface of the spheres by grafting, similarly to other alkoxysilanes, through a standard silanoxane coupling mechanism. ${ }^{37}$ The reaction of the functional silane with the silanol groups present on the silica surface was performed in toluene under reflux condition, yielding LP-MSN-E. (2) PLL was then attached to silica via nucleophilic addition to the epoxyde sites of the 3-GPS. The interaction between PLL and the epoxysilane is ensured by the nucleophilic attack of the nonbonding electron pair of nitrogen atoms on strained acidic carbons in the epoxy ring causing the ring to open. ${ }^{38}$ After proton migration, the required product is obtained (LP-MSN-P). ${ }^{38}$ (3) The resulting composites of LP-MSNs and PLL can then be used as a DNA/siRNA carrier. In addition, amine functionalized LP-MSN (LP-MSN-A) was prepared by standard grafting of APTES in toluene. ${ }^{16}$

Figure 1 panels $C, E$, and $G$ show SEM images of the functionalized LP-MSNs samples (LP-MSN-E, LP-MSN-P, and LP-MSN-A, respectively). The images reveal that the functionalization process does not affect the spheroid-like morphology of LP-MSNs. Furthermore, the TEM images (Figure $1 \mathrm{D}, \mathrm{F}$, and $\mathrm{H}$ ) also indicate that the cubic pore structure, pore size, particle size, and particle morphology are all well preserved for the functionalized particles. Most importantly, the nitrogen sorption data show that the functionalization of LP-MSNs with different organic species (APTES and PLL) did not result in pronounced obstruction of the materials porosity (Supporting Information, Figure S1). Clearly, the organic functionalized LP-MSNs (LP-MSN-A and (P-MSN-P) still preserved the structure of the native silica material (LP-MSNs). However, the attachment of the organics affected specific surface area, pore volume, and pore size, these values being smaller for the functionalized samples (Table 1). The main reason is the presence of the organic compound both on the external and internal surface of the silica ${ }^{9,38}$ The functionalization of LP-MSNs with PLL (1-4 kDa) caused a pore diameter reduction from 13.4 to $11.8 \mathrm{~nm}$. This result is in good agreement with previous research by Karl et al. who showed that functionalization of SBA-15 by using different molecular weights of PLL (from 3 to $6 \mathrm{kDa}$ ) caused a pore diameter reduction of ca. $1-2 \mathrm{~nm}^{27}$ TG-DTA analysis of LP-MSN-P (Supporting Information, Figure S3) confirms the PLL attachment on the LP-MSNs. The analysis shows a mass loss of $7 \%$ (the percent weight does not include the percent weight of epoxysilane). On the other hand, amine functionalization resulted in a pore size decrease of LP-MSNs to $11.3 \mathrm{~nm}$. On the basis of the thermogravimetric analysis (TGA) analysis, the loading amount of amine silane grafted into LP-MSNs was almost double than that of PLL with a weight loss up to $13 \mathrm{wt} \%$. Both functionalization procedures (PLL and APTES) also affected the uniformity of the mesopore cavities resulting in wider pore size distributions (Supporting Information, Figure S1). 


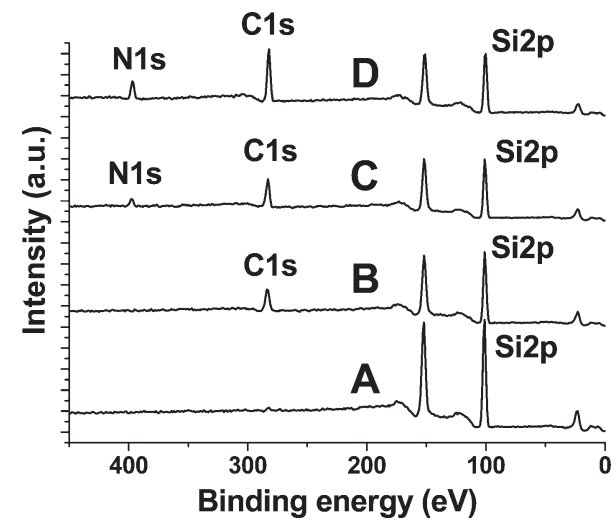

Figure 2. XPS spectra of (A) LP-MSNs, (B) LP-MSN-E, (C) LP-MSN-P, and (D) LP-MSN-A.

Nature of the PLL and APTES Attachment onto LP-MSNs. The PLL groups should provide the silica surface with sufficient quantity of positive charges to achieve relatively strong interactions with siRNA. Yet at the same time, the amount of PLL groups should remain low enough in order to limit toxicity exposure. A low molecular weight of PLL $(1-4 \mathrm{kDa})$ was used because lower molecular weights of polycations are known to induce lower toxicity. ${ }^{7,39}$ A previous study on the toxicity of PLL with different molecular weights (2.9 and $27.4 \mathrm{kDa}$ ) indicates that low molecular weight PLL (2.9 kDa) has lower cytotoxicity vs human cell lines as compared to higher molecular weight PLL. ${ }^{40}$ As shown in Table 1, the introduction of PLL which contains amine moieties produced positive charges on the silica surface, resulting in a positive LP-MSN-P potential value $(+1.9 \mathrm{mV}$ as compared to LP-MSNs with $-17.3 \mathrm{mV}$ ). The grafting of the aminosilane (APTES) on the silica surface also produced a positively charged surface $(+3.23 \mathrm{mV})$. The positive charges are expected to permit adsorption of negatively charged DNA and siRNA, as discussed below.

The X-ray photoelectron spectroscopy (XPS) analyses of four different samples (LP-MSNs, LP-MSN-E, LP-MSN-P, and LP-MSN-A) provide evidence of the attachment of the organic compounds on the silica surface (Figure 2 and Table 2). The spectra of the functionalized LP-MSNs show a strong C1s peak which reflects the increasing amount of organics on the silica surface. Specifically, the incorporation of APTES and PLL results in an intense peak associated to N1s. The atomic composition of these samples is given in Table 2. Small content of C1s in LP-MSNs may be ascribed to residual surfactant species. ${ }^{9}$ The introduction of the epoxysilane (3-GPS) into silica leads to an increase in atomic percent of $C$ concentration (13.7\%). The grafting with PLL further increases the carbon percentage (14.80\%) and the N1s atom signal emerges with a concentration of $2.47 \%$. The atomic weight percentage of $\mathrm{N}$ in LP-MSN-A is double than that of LP-MSN-P. This result is in good agreement with the TGA analysis, and it
TABLE 2. Elemental Composition of LP-MSNs and Functionalized Materials

\begin{tabular}{lrccc} 
& \multicolumn{4}{c}{ element content (atom \%) } \\
\cline { 2 - 5 } sample & C1s & 01s & Si2p & N1s \\
\hline LP-MSNs & 1.30 & 69.02 & 29.67 & \\
LP-MSN-E & 13.17 & 61.16 & 25.67 & \\
LP-MSN-P & 14.80 & 58.16 & 24.57 & 2.47 \\
LP-MSN-A & 24.94 & 46.29 & 23.81 & 4.96 \\
\hline
\end{tabular}

${ }^{a}$ XPS analysis.

explains why LP-MSN-A has higher zeta potential value than LP-MSN-P (Table 1).

Figure 3 shows the solid state ${ }^{13} \mathrm{C}$ charge-polarized magic angle spinning nuclear magnetic resonance (CP-MAS NMR) spectra of LP-MSN-E, LP-MSN-P, and LP-MSN-A. The data confirm successful anchoring of the organic compounds on the silica surface. The presence of epoxy-silane (3-GPS) can directly be judged from two distinct peaks $C^{5}$ and $C^{6}$ with chemical shifts of 50.64 and 43.45 ppm, respectively (Figure $3 \mathrm{~A}$ ). These peaks reveal the presence of the carbon atoms of the epoxide ring. ${ }^{41}$ The other peaks corresponding to $C^{1}$ (7.88 ppm), $C^{2}$ (22.18 ppm), $C^{3}$ and $C^{4}$ (72.56 ppm) also corroborate the chemical structure of $3-G P S .{ }^{41}$ Figure $3 \mathrm{~B}$ represents the ${ }^{13} \mathrm{C} C P-M A S$ NMR spectra of LP-MSN-P. It can be seen that the two peaks at 43.45 and 50.64 disappeared, which is an indication that the epoxy ring was opened and the PLL was properly anchored. ${ }^{41}$ The presence of PLL can be seen from the carbonyl $(C=O)$ peak at $173.61 \mathrm{ppm}^{42}$ The other peaks observed for $C \alpha(53.76 \mathrm{ppm}), \mathrm{C} \beta(27.24 \mathrm{ppm}), \mathrm{C} \gamma$ (26.12 ppm), $C \delta$ (30.24 ppm), and $C \varepsilon$ (39.83 ppm) also belong to PLL. ${ }^{42,43}$ Some peaks at $9.01\left(C^{1}\right), 22.56\left(C^{2}\right)$, and $72.75\left(C^{3}+C^{4}\right)$ ppm can be attributed to remaining 3-GPS. The chemical shifts of the ${ }^{13} C$ NMR resonances of the LP-MSN-E and LP-MSN-P samples are compiled in Table 3. Similarly, the covalent attachment of the aminosilane (APTES) is proven by three peaks with the chemical shift 11.02, 26.10, and 44.34 ppm (Figure $3 C$ ), which can be ascribed to the carbon atoms $C^{1}, C^{2}$, and $\mathrm{C}^{3}$ (i.e., $\mathrm{Si}-\mathrm{O}-\mathrm{Si}-\mathrm{C}^{1}-\mathrm{C}^{2}-\mathrm{C}^{3}-\mathrm{NH}_{2}$ ). ${ }^{9}$

The sequence of epoxysilane grafting followed by PLL attachment can also be verified by transmission FTIR. Supporting Information, Figure S4 shows the spectra obtained from three different samples: LP-MSNs, LP-MSN-E, and LP-MSN-P. Silanol ( $\mathrm{Si}-\mathrm{OH})$, $\mathrm{Si}-\mathrm{O}-\mathrm{Si}$, and $\mathrm{O}-\mathrm{Si}-\mathrm{O}$ bands from the parent material (LP-MSNs) are observed at 3400, 1094, and $470 \mathrm{~cm}^{-1}$, respectively. ${ }^{26,44}$ The main characteristic band assigned to the epoxy group at around $1150 \mathrm{~cm}^{-1}$ is, however, overlapped by the strong absorption of silica. Alkyl $\mathrm{C}-\mathrm{H}$ stretching and the corresponding bending vibrations are detected at 2944, 1343, and $1465 \mathrm{~cm}^{-1}$, respectively. ${ }^{44}$ Furthermore, the presence of the PLL on the surface of the silica samples can be identified 

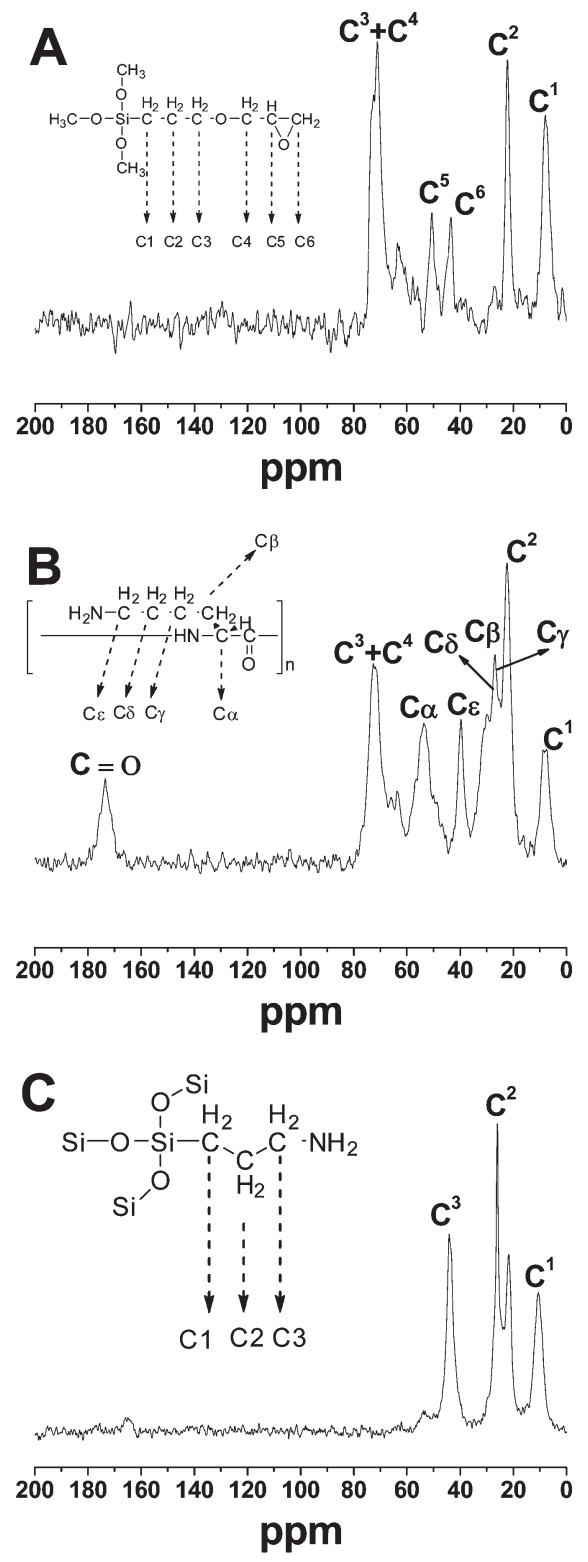

Figure 3. Solid state ${ }^{13}$ C CP NMR spectra of (A) LP-MSN-E, (B) LP-MSN-P, (C) LP-MSN-A.

TABLE 3. Summary of Resonance of ${ }^{13} \mathrm{C}$ CP NMR Spectra for LP-MSN-E and LP-MSN-P Samples

$\begin{array}{llllllll}\text { LP-MSN-E } & \text { C1 } & \text { C2 } & \text { C3 } & \text { C4 } & \text { C5 } & \text { C6 }\end{array}$ $\begin{array}{lllllll}\text { chemical shift (ppm) } & 7.88 & 22.18 & 72.56 & 72.56 & 50.64 & 43.45\end{array}$ $\begin{array}{llllllll}\text { LP-MSN-P } \quad & \quad=0 & C \alpha & C & C & C & C \delta & C \varepsilon\end{array}$ $\begin{array}{lllllll}\text { chemical shift (ppm) } & 173.61 & 53.76 & 27.24 & 26.12 & 30.34 & 39.83\end{array}$

through the presence of an amide-l peak at $1680 \mathrm{~cm}^{-1}$ and the amide-II peak at $1540 \mathrm{~cm}^{-1}$. The amide-l is due to $\mathrm{C}=\mathrm{O}$ stretching, while the amide II arises from $\mathrm{C}-\mathrm{N}$ stretching and $\mathrm{N}-\mathrm{H}$ bending. ${ }^{45}$ These two peaks confirm the attachment of the PLL on the LP-MSNs.

DNA Adsorption and Cellular Uptake. First, the affinity of LP-MSNs and its functionalized counterparts to 21nucleotide long (oligo) DNA (a model for siRNA) was measured by adsorption. Figure 4 shows the results of

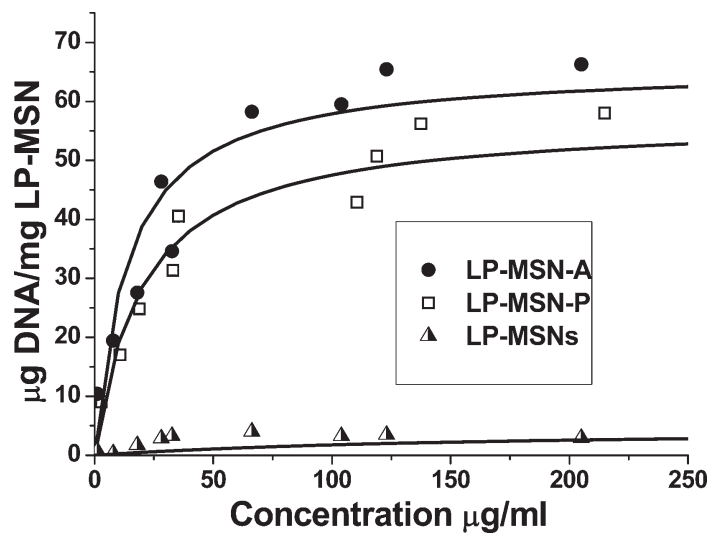

Figure 4. Oligo DNA adsorption against LP-MSNs, LP-MSN-A, and LP-MSN-P.

the oligo DNA adsorption in LP-MSNs and the functionalized forms (LP-MSN-A and LP-MSN-P). Interestingly, LP-MSN-P shows a very high adsorption capacity for the oligo DNA $(57 \mu \mathrm{g} / \mathrm{mg}$ or $1.56 \mathrm{nmol}$ per $175 \mu \mathrm{g}$ LP-MSN-P). Noteworthy, the adsorption amount of LP-MSN-P was almost five times higher compared to the polyethyleneimine functionalized MSNs (PEI-MSN) materials reported previously. ${ }^{12}$ The presence of PLL increases the particle affinity toward the gene. It is believed that the synergy between the large pore size of LP-MSNs and the PLL functionalization contributed to this significant difference. It has been found before that large plasmid DNA (5256 bp) can be internalized within LP-MSNs with an entrance pore size of $5.7 \mathrm{~nm} .{ }^{15}$ Thus, it is expected that LP-MSN-P with a larger entrance size $(11.8 \mathrm{~nm})$ can adsorb oligo DNA with 21 base pairs in higher amounts compared to the small pore PEI-MSNs.

It is also interesting to note that the adsorption capacity of LP-MSN-P was almost equal to that of LP-MSN-A, although LP-MSN-P has lower amine concentration and a lower zeta potential value. There are several reasons to explain such an enhanced performance of LP-MSN-P compared to LP-MSN-A. First, the interaction between LP-MSN-A and oligo-DNA are mainly electrostatic, whereas the strong interactions between LP-MSN-P and the oligo-DNA are originating from the combination of electrostatic interactions and specific binding of PLL to the A-T (adenine-thymine) sequences of DNA. Indeed, previous reports have confirmed that other binding forces come into play between polycations and DNA strands besides electrostatic forces, that is, the selectivity of PLL for A-T sequences and poly-L-arginine for G-C (guanine-cytosine) sequences. ${ }^{46-48}$ The association of the electrostatic interactions and selective binding confers LP-MSN-P strong affinity to oligo-DNA, resulting in increased adsorption amounts. Second, the major advantage of LP-MSN-P in comparison to LP-MSN-A in terms of interfacial contact with oligo-DNA is the presence of PLL, which possesses a 3-D polymeric 


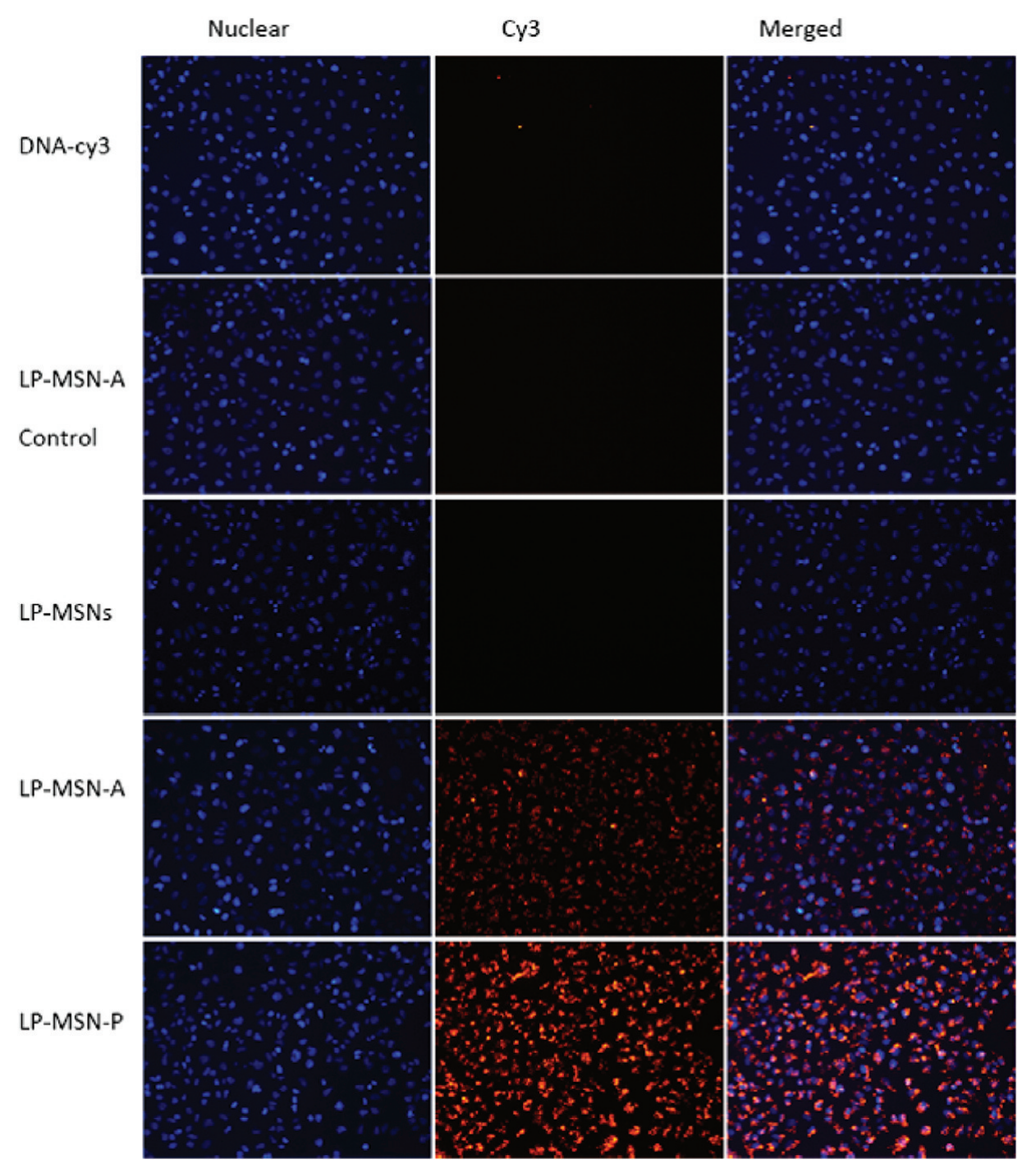

Figure 5. Cell uptake of LP-MSNs and functionalized counterparts. The cell up-take efficiency of LP-MSNs, LP-MSN-P, and LP-MSN-A were examined by labeling the particles with a 21-nt oligo DNA conjugated with Cy-3. The oligo DNA-Cy3 (DNA-Cy3) or LP-MSN-A alone is negative for Cy3 signal. LP-MSNs are unable to carry oligo DNA-Cy3 thus no Cy3 signal is observed. LP-MSN-A with oligo DNA-Cy3 shows positive signal. LP-MSN-P is more effective to adsorb DNA-Cy3 and has the strongest Cy3 signal.

structure. The existence of numerous amine groups along the PLL chains generates multiple accessible reaction sites. This 3-D reactive structure provides several attachment sites for the genes. ${ }^{49}$ In contrary, functionalization with APTES only introduces linear and short aminoalkyl chains on the silica surface that induce a relatively planar surface structure. This type of organization seems to afford a more restricted environment for DNA/siRNA attachment, ${ }^{50}$ therefore increasing steric hindrance between the DNA molecules, and thus limiting their adsorption. As a result of multiple accessible attachments, LP-MSN-P keeps a very high adsorption capacity.

The cell internalization capacity of functionalized LP-MSNs was also studied in the case of cancer cells (HeLa cells). To adequately follow adsorption and the cell internalization process, oligo-DNA was labeled with cyanine dye (Cy3). Figure 5 illustrates the cell uptake study of LP-MSNs and the functionalized equivalents. It is observed that there is no Cy3 signal from native LP-MSNs. In contrast, the modified LP-MSNs (LP-MSN-A and LP-MSN-P) revealed dye signals. Among the functionalized materials, LP-MSN-P produced the strongest $\mathrm{Cy} 3$ signals. The strong signals of the oligo DNA-LP-MSN-P complex were found in most of the cancer cells which indicates that most of the cells have been transfected. The strong signal is generated from the high concentration of the complexes which can be internalized within the cells. In contrary, Figure 5 also shows that oligo DNA-LP-MSN-A did not give equivalently strong signals, assuming that it was due to the reduced internalization of oligo DNA-LP-MSN-A complex. Figure 5 shows that the signal from the LP-MSN-A complex is not distributed equally throughout the cells. This result suggests that LP-MSN-A could not be adequately internalized within most of the cells. It is 

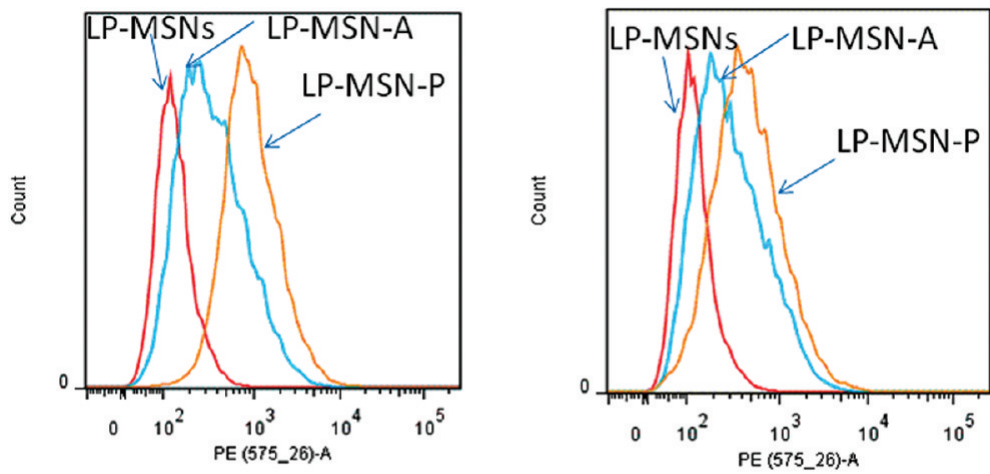

\begin{tabular}{|l|l|l|l|l|l|l|}
\hline \multicolumn{1}{|c|}{ Groups } & NP-C & siR-C & $\begin{array}{l}\text { LP- } \\
\text { MSNs }\end{array}$ & $\begin{array}{l}\text { LP- } \\
\text { MSN-A }\end{array}$ & $\begin{array}{l}\text { LP- } \\
\text { MSN-P }\end{array}$ \\
\hline MFI & No treat. & 176 & 201 & 183 & 334 & 481 \\
\hline & Treated & 147 & 174 & 138 & 293 & 438 \\
\hline $\begin{array}{l}\text { Pos. } \\
\text { cells } \\
(\%)\end{array}$ & No treat. & $0.51 \%$ & $1.52 \%$ & $0.67 \%$ & $47.5 \%$ & $68.1 \%$ \\
\hline
\end{tabular}

Notes: MFI: mean fluorescent Intensity. Pos. cells: Cy3 positive cells (\%).

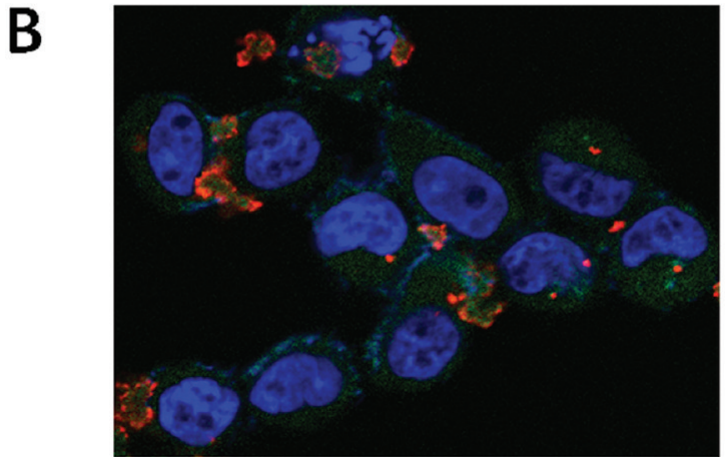

Figure 6. Assessments of cell uptake by flow cytometry analysis and confocal microscopy. The internalization of Cy3-labeled oligo DNA-LP-MSN and functionalized counterparts (LP-MSN-A and LP-MSN-P) in HeLa cells were observed by flow cytometry (A) and confocal microscopy (B). The confocal image shows localization of nanoparticle (LP-MSN-P) delivered oligo-DNA-Cy3 (red color) in HeLa cells, while the nuclear are stained blue (DAPI) and the cell membrane is stained green (FITC).

thus obvious that LP-MSN-A is not as effective as LP-MSN-P as a gene carrier for cancer cell uptake. Furthermore, the negatively charged native LP-MSNs could not interact at all with the negatively charged cell surface and did not undergo cell internalization, resulting in no signal detected.

Furthermore, the cellular uptake of Cy3-labeled oligo DNA-LP-MSNs and functionalized counterparts (LP-MSN-A and LP-MSN-P) into HeLa cells were assessed by flow cytometry (Figure 6 A) and confocal microscopy (Figure 6 B). Flow cytometry analysis reveals that PLL and amine functionalization resulted in a clear shift in the MFI (mean fluorescent intensity). The analysis consists of two parts: with quenching treatment and without quenching treatment. The results show clearly (Figure $6 \mathrm{~A}$ ) that LP-MSN-P exhibits the most strong fluorescent signals and has a highest percentage of positive cells $(60-70 \%)$ as compared to the other two groups (amine modified and nonmodified). Quenching treatment with DNase I (as Cy 3 was conjugated to oligo DNA) only slightly reduced the fluorescent intensity and positive cell numbers but did not change the trend. It is noted that the fluorescein-activated cell sorting (FACS) analysis was performed on BD LSR II analyzer that was set up to detect emission signals of PE (575/26). This was the only good channel to detect Cy3 but not the best. Therefore the real fluorescent intensity or positive cell percentage would be expected to be higher.

In addition, the successful internalization of Cy3labeled oligo DNA-LPMSN-P can also be observed by confocal microscopy (Figure 6B). The image from the microscopy shows that most red signals (Cy3) are within the cells. To further confirm this, we also stained 


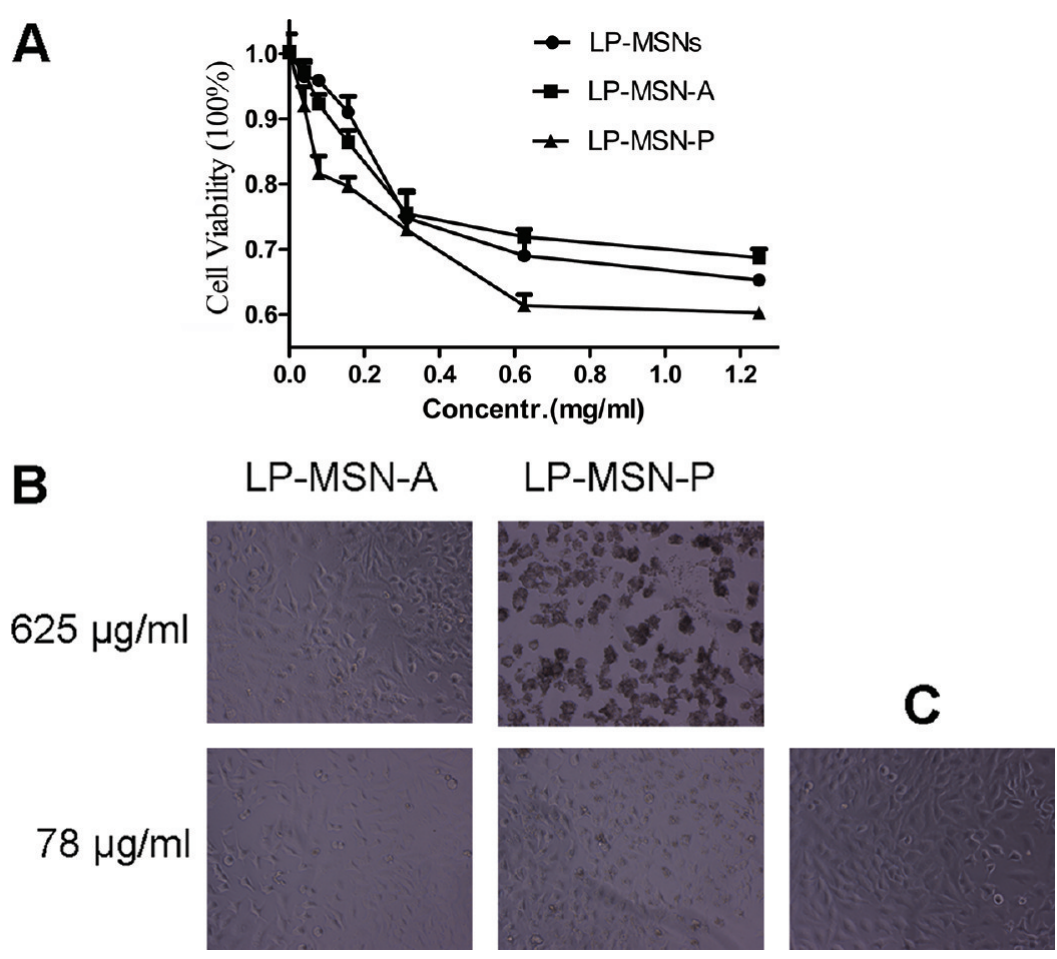

Figure 7. Cytotoxicity of LP-MSNs and functionalized counterparts. (A) The assay results show the cell viability (\%) after 24-h treatment with different doses of LP-MSNs, LP-MSN-A, or LP-MSN-P. (B) Cell (HeLa) images: cytotoxicity comparison between LP-MSN-A and LP-MSN-P at different concentrations. (C) Cell image with LP-MSNs treatment.

the cells with anti-CD24 antibody conjugated with fluorescein isothiocyanate (FITC). CD24 is a cell membrane protein. It can be seen clearly that most red signals are separated from green (FITC) though there are a few colocalization (yellow) cases, suggesting that most Cy3s are internalized. These results confirm that LP-MSN-P has the highest cellular uptake compared to LP-MSN-A and LP-MSNs.

Even though the oligo DNA adsorption study indicates that LP-MSN-A had strong interactions with oligo DNA, the fact that the LP-MSN-A complex only generated less signals should (Figure 5 and Figure 6A) be related to the less effective cell uptake. PLL-functionalization had significantly enhanced cell uptake as compared to the amine functionalization. The enhancement is believed to be caused by the favored interfacial interactions between PLL and the cancer cell surface. The multiple accessible reactive sites of PLL not only support the material's interactions with the oligo DNA but also induce stronger interactions with the negatively charged cell surface. These strong interactions lead to efficient wrapping of the silica particles which in turn lead to higher cellular uptake. ${ }^{7}$ In contrast, in the case of LP-MSN-A, the strong interactions between LP-MSN-A and oligo-DNA result in most of the positively charged amines being covered by the DNA. These results agree well with previous findings reported by Martin et al. who showed that the functionalization of iron oxide particles with longer chain molecular structure of guanidine dendron has a beneficial influence on cell uptake as compared to shorter amine dendrons. ${ }^{51}$ More elongated and flexible dendron structure permitted more favorable interactions with the cell surface leading to higher cell uptake.

To conclude, the results of the adsorption and cell uptake experiments establish that surface modification of LP-MSNs is indeed crucial in order to efficiently adsorb and to deliver oligo-DNA into cancer cells. Our results emphasize the high efficiency of LP-MSN-P in adsorbing oligo DNA as a model for siRNA and interacting with cancer cells with enhanced cellular uptake. Clearly, cell internalization capability of LP-MSN-P is far superior to both LP-MSN-A and LP-MSNs. The high transfection of oligo DNA-LP-MSN-P in a dense cell population suggests that the LP-MSN-P could truly be promising as a gene carrier for gene therapy applications. However, the cytoxocity of the system must first be evaluated (see below).

Cytotoxicity Study. To evaluate the cytotoxicity of the LP-MSNs, we used a cervical cancer cell line SiHa. The cell viability test (Figure $7 \mathrm{~A}$ ) results demonstrate that the toxicity of LP-MSNs and its functionalized forms are determined by their concentration. The cytotoxicity was increased as the nanoparticle concentration increased. The results are further confirmed by the cell images (Figure 7B), i.e., at high concentrations (>300 $\mu \mathrm{g} / \mathrm{mL}$ ) all nanoparticles were toxic to some extent to the cells. However, at lower concentrations $(<100 \mu \mathrm{g} / \mathrm{mL})$, the three samples had low cytotoxicity. 
A

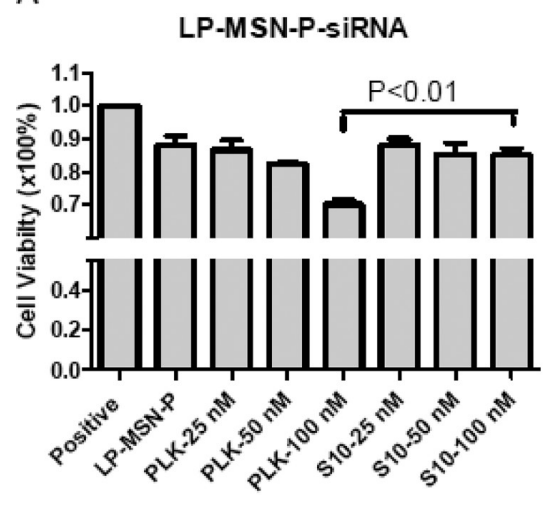

B

LP-MSN-A-SiRNA

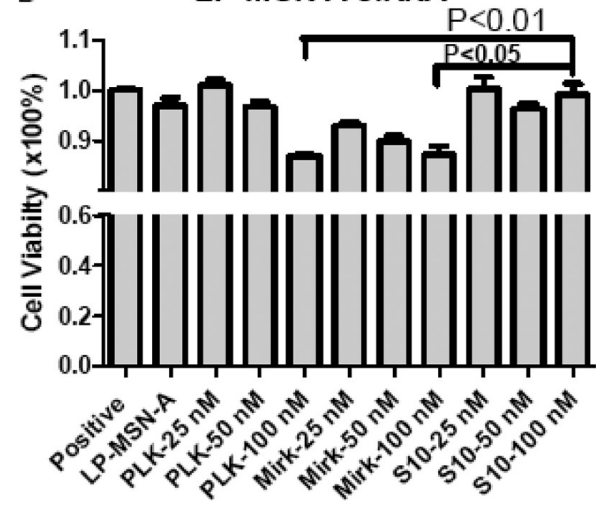

Figure 8. Biological function analysis of LP-MSNs and functionalized counterparts by delivering siRNAs. The LP-MSN-P and LP-MSN-A were loaded with functional siRNA against oncogenes PLK and Mirk that are overexpressed in osteosarcoma cell line KHOS. Three siRNA loading concentrations $(25,50$, and $100 \mathrm{nM})$ were tested. Positive control was the cell viability without any siRNA and particle treatment. S10-siRNA was used as a negative control: (A) LP-MSN-P; (B) LP-MSN-A. The $P$ values are from Student's $t$ test.

Figure 7 indicates that LP-MSN-P is more toxic than LP-MSN-A and the native LP-MSNs. The toxicity of LP-MSN-P is related to the cationic charge from the primary amine surface groups. ${ }^{52}$ However, the primary amine will only start inducing toxicity upon strong interactions with the cell membrane. As mentioned above, the molecular structure of PLL yields numerous accessible primary amine sites from each monomer moiety present in the polymer structure (lysine). Although these accessible amine sites have the advantages of inducing strong interactions with the cell membrane (leading to high cell uptake), it is also responsible for increased cytotoxicity.

In light of this cytotoxicity study and in relations to the application of polycation as gene carriers, it is therefore very important to moderate the impact of PLL. One of the methods to achieve this is through a careful selection of the molecular weight of PLL and the complex particle concentration. LP-MSN-P materials which was modified using low molecular weight of PLL (1-4 kDa) show high biocompatibility at concentrations below $<100 \mu \mathrm{g} / \mathrm{mL}$. Fortunately, the high loading capacity of siRNA within the LP-MSN-P will support siRNA efficacy even at a low particle concentration.

Delivery of siRNA to Cells. To investigate whether the LP-MSNs system could deliver biofunctional siRNA for therapeutic applications, we used the nanoparticles to deliver siRNAs against polo-like kinase 1 (PLK1) and minibrain-related kinase (Mirk) and tested gene silencing effect in osteosarcoma cell line KHOS cells. These two oncogenic genes are highly expressed in osteosarcoma cells and silencing them with siRNAs can inhibit KHOS cell growth. ${ }^{53,54}$ For control, we chose another siRNA, S10, which was reported by some of us as an effective siRNA against human papillomavirus (HPV) type 16 E6 gene. ${ }^{55}$ At first, we tested the effectiveness of LP-MNS-A in transferring both PLK1- and
Mirk-siRNAs. As illustrated in Figure 8, compared to controls (including LP-MSNs alone and S10-siRNA controls), LP-MSN-A could deliver both PLK1- and Mirk-siRNAs and induced a noticeable decrease of cell viability at high siRNA concentrations (100 nM). At this concentration, LP-MSN-A was able to reduce cell viability by around $15 \%$. LP-MSN-P was then also tested to deliver PLK1 siRNA. The positive control of LP-MSN-A and LP-MSN-P shows that the particle toxicity contributed to mild decrease of cellular viability namely $5 \%$ and $10 \%$ for LP-MSN-A and LP-MSN-P, respectively. Most importantly, LP-MSNP-P showed a better performance compared to LP-MSN-A by revealing higher reduction of cellular viability at $30 \%$ which is double than that of LP-MSN-A.

One of the reasons of the observed higher gene expression of LP-MSN-P compared to LP-MSN-A is the high cell uptake of LP-MSN-P. The main prerequisite for siRNA to express their biofunction is by transferring the siRNA into the cytoplasm. ${ }^{4,56}$ Increase in cell uptake will lead to an increased delivery of siRNA into the cytoplasm. Furthermore, it has been reported that PLL can cause the fusion of the membrane leading to the destabilization of the endosomonal membrane. ${ }^{24,57,58}$ The presence of PLL could thus boost endosomonal break out of the particles which ultimately increases particle release into the cytoplasm. In turn, these two factors (high cell uptake and endosomonal escape) are believed to increase siRNA accumulation within the cytoplasm and enhance the gene silencing effect. However, knockdown of oncogenes still need to be improved. The general problem with the polycation as siRNA carrier is the less efficient release of siRNA from the complex. Polycations (PLL, PEI) have strong affinity toward genes (siRNA/DNA). It is known that the strong interactions between carriers and genes could lead to a difficult disassembling of the biological molecules, which in turn affects the knock down efficiency/gene 
silencing. ${ }^{59}$ One of the most important phases in drug/ gene delivery into cells is the so-called vector unpackaging. The problematic part is to design a carrier which has strong affinity versus siRNA, yet the bonding between them should not limit the disassembly of siRNA from the LP-MSNs once the complex get into the cell cytoplasm. To overcome the current LP-MSN-P limitation, further studies are still needed to confirm the possibility for substituting PLL with more degradable polycations or other polymers. A degradable structure is expected to enhance siRNA release from the polymer and also reduce the associated toxicity.

Another issue for in vivo application of LP-MSN-P is colloidal particle stability. Our study indicates that LP-MSN-P shows better performance compared to LP-MSN-A in terms of dispersibility (Supporting Information, Figure S5) and minor aggregation of LP-MSN-P was observed. This minor aggregation might lower the effectiveness of LP-MSN-P as a siRNA carrier because the aggregate particles have shorter in vivo circulation time as compared to well-dispersed particles. Further work is underway to perform optimization of the LP-MSNs system, including optimizing PLL concentration to achieve electrostatic stability and introducing poly(ethylene glycol) (PEG) on the particle's surface to induce "stealth" properties thus improving the particle's circulation time.

\section{CONCLUSIONS}

We demonstrated in this study that functionalized large pore mesoporous silica nanoparticles with cubic mesostructure have a true potential for delivery of nucleic acids in high concentration. The PLL functionalized LP-MSNs have a strong binding capacity to negatively charged nucleic acid while creating strong interactions with the negatively charged cell surface membrane. As a result, cellular uptake is enhanced. The nanoparticles had an excellent rate of cells transfection in which most of the cells in the population have been affected. The use of large pores clearly improved adsorption of oligo DNA (a DNA model for siRNA). The adsorbed amount achieved was significantly higher compared to small pore size mesoporous silica nanoparticles reported previously. Moreover, PLL functionalization showed superior cancer cell transfection compared to aminefunctionalized equivalents. The functionalized nanoparticles showed low cytotoxicity at concentrations up to $100 \mu \mathrm{g} / \mathrm{mL}$. Furthermore, a reasonable reduction of cellular viability of oncogenes in cancer cells has been demonstrated by delivery of siRNA using the PLL functionalized LP-MSNs. Therefore, we have designed nanostructured vector carriers with large internal pore space enabling the inclusion of various biomolecules and possessing adequate surface functionalization suitable for dual delivery of drug and genes. In addition to the therapeutic reagents, the large pores of the LP-MSNs may also be used to simultaneously host specific contrast agents (e.g., MRI tracking), optical probes, or magnetic nanoparticles for future targeted delivery and theranostic applications.

\section{MATERIALS AND METHODS}

Chemicals. Triblock poly(ethylene oxide)-b-poly(propylene oxide)- $b$-poly(ethylene oxide) copolymer $\mathrm{EO}_{106} \mathrm{PO}_{70} \mathrm{EO}_{106}$ (pluronic F127, MW = 13400), tetraethoxysilane (TEOS, 99\%), 1,3,5-trimethylbenzene (TMB), 3-aminopropyltriethoxysilane (APTES, 99\%), 3-glycidoxypropyl trimethoxysilane (3-GPS), and poly-L-lysine (PLL) were purchased from Sigma Aldrich. Fluorocarbon surfactant (FC-4) was purchased from Yick-Vic Chemicals \& Pharmaceuticals (H.K.) Ltd. All chemicals were used as received without purification. Cell lines used including cervical cancer cell lines HeLa (ATCC, CCL-2), SiHa (ATCC, HTB-35) cells, and osteosarcoma cell line KHOS/NP (CRL-1544) were purchased from ATCC (American Type Culture Collection). Twenty-one-nucleotide (oligo) DNA conjugated with cyanine dye (Cy-3), fetal calf serum, paraformaldehyde, and antifade fluorescent mounting medium with 4'-6-diamidino-2-phenylindole (DAPI) were purchased from Sigma Aldrich. Dulbecco's Modified Eagle's Medium (DMEM) and penicillin G, streptomycin sulfate, and L-glutamine mixture were from GibcoInvitrogen. CellTiter-Glo cell viability assay kit was from Promega. Synthetic human PLK1 and Mirk siRNAs were purchased from Ambion at Applied Biosystems (Foster City, CA). The siRNA sequences are PLK-S, 5'-CCAUUAACGAGCUGCUUAATT-3'; PLK-AS, 5'-UUAAGCAGCUCGUUAAUGGTT-3'; Mirk-S, 5'-GGCACUUCAUGUUCCGGAATT-3'; Mirk-AS, 5'-UUCCGGAACAUGAAGUGCCGC-3'. S10-siRNA was synthesized by Proligo (Lismore, Australia) and the sequences are as follows:
S10-S, 5'-GCAACAGUUACUGCGACGUUU-3'; S10-AS, 5'-ACGUCGCAGUAACUGUUGCUU- 3'.

Synthesis of LP-MSNs. The synthesis of LP-MSNs with cubic mesostructure followed the method previously reported by Gao et $a .^{15}$ First, $0.5 \mathrm{~g}$ of F127 and $1.4 \mathrm{~g}$ of FC-4 were dissolved in $60 \mathrm{~mL}$ of $0.02 \mathrm{M} \mathrm{HCl}$ and stirred for $24 \mathrm{~h}$ at $60^{\circ} \mathrm{C}$. A $0.4 \mathrm{~g}$ portion of $\mathrm{TMB}$ was added into the mixture and stirred at a low temperature of $10^{\circ} \mathrm{C}$ for $6 \mathrm{~h}$. Then, $3 \mathrm{~g}$ of TEOS was added to the solution, and the stirring process at $10^{\circ} \mathrm{C}$ was continued for another $24 \mathrm{~h}$. The solution was then transferred into autoclaves for the hydrothermal treatment. The first hydrothermal temperature was at $150^{\circ} \mathrm{C}$ for $24 \mathrm{~h}$ which then followed by second hydrothermal treatment at $140{ }^{\circ} \mathrm{C}$ for $48 \mathrm{~h}$. The sample was denoted as LP-MSNs.

Epoxysilane (3-GPS) Functionalized LP-MSNs (LP-MSN-E). A $300 \mathrm{mg}$ portion of LP-MSNs was added into $25 \mathrm{~mL}$ of toluene. The mixture was first sonicated to facilitate dispersion, then $0.4 \mathrm{~mL}$ of 3-GPS was added. After $15 \mathrm{~min}$, the mixture was refluxed at $70^{\circ} \mathrm{C}$ for $24 \mathrm{~h}$. The solid products were centrifuged, washed with toluene and methanol for three times, and dried. The sample was denoted as LP-MSN-E.

PLL Functionalized LP-MSNs (LP-MSN-P). To prepare PLL-functionalized LP-MSNs, a stock solution of PLL and LP-MSN-E was first prepared. The concentration of PLL in carbonate buffer solution ( $50 \mathrm{mM}$, pH 9.5) was $5 \mathrm{mg} / \mathrm{mL}$, while the LP-MSN-E solution was prepared at $10 \mathrm{mg} / \mathrm{mL}$ in the same buffer solution. Then, $2 \mathrm{~mL}$ of PLL peptide solution was mixed with $4 \mathrm{~mL}$ of the LP-MSN-E solution. The mixture solution was stirred at room temperature 
for $24 \mathrm{~h}$. After this step, the solid product was produced and washed with $20 \mathrm{~mL}$ of $1.0 \mathrm{M} \mathrm{NaCl}$ and water, and then centrifuged. At the final stage, the solid products were suspended in $20 \mathrm{~mL}$ of $1.0 \mathrm{M}$ ethanolamine $(\mathrm{pH} 9)$ and stirred at room temperature for $6 \mathrm{~h}$ to block unreacted epoxy groups. The solids were then again washed with $20 \mathrm{~mL}$ of $1.0 \mathrm{M} \mathrm{NaCl}$ and $20 \mathrm{~mL}$ of water. The sample was denoted as LP-MSN-P.

Amine-Functionalized LP-MSNs (LP-MSN-A). One gram of LP-MSNs was dispersed in $50 \mathrm{~mL}$ of toluene. The mixture was first sonicated to facilitate dispersion. It was heated to $50{ }^{\circ} \mathrm{C}$, then, $1 \mathrm{~mL}$ of APTES was added and heated to $110{ }^{\circ} \mathrm{C}$. The reflux process was continued for $16 \mathrm{~h}$. The solid products were collected via the centrifuge and washed 5 times with acetone to remove toluene. The sample was then dried in oven at $50{ }^{\circ} \mathrm{C}$ and denoted as LP-MSN-A.

Oligo DNA Adsorption into LP-MSNs and Functionalized LP-MSNs. The adsorption isotherm was determined by preparing a series of oligo DNA solutions with various concentrations ranging from 40 to $650 \mu \mathrm{g} / \mathrm{mL}$ in PBS buffer at $\mathrm{pH} 7.4$. As much as $1 \mathrm{mg}$ of LP-MSNs was then mixed with $250 \mu \mathrm{L}$ of each oligo DNA solutions in $1.5 \mathrm{~mL}$ centrifuge tube. The mixture was dispersed by vortex for $30 \mathrm{~s}$ and incubated in a shaker with a $200 \mathrm{rpm}$ shaking speed at $25^{\circ} \mathrm{C}$ for $24 \mathrm{~h}$. Suspensions were separated by centrifugation at $14800 \mathrm{rpm}$ for $5 \mathrm{~min}$. The difference of the oligo DNA amount in solution before and after adsorption was deemed equal to the amount of oligo DNA adsorbed on the material.

Cell Uptake Assay. The assays were carried out in 6-well cell culture plates. HeLa cells were seeded in plates at $2 \times 10^{5}$ cells per well the day before the assay. The particles (LP-MSNs, LP-MSN-P, and LP-MSN-A) were diluted in phosphate buffered saline (PBS) at a concentration of $1 \mathrm{mg} / \mathrm{mL}$, and $100 \mu \mathrm{L}$ of the resulting mixture was used for each well. A 21-nucleotide long (oligo) DNA conjugated with cyanine dye (Cy-3) was used as a template for short interfering RNA (siRNA) and was diluted in the $100 \mu \mathrm{L}$ of particle solution to give final oligo DNA concentrations of $50 \mathrm{nM}$ and $100 \mathrm{nM}$. The solution was mixed well and incubated at room temperature for $4 \mathrm{~h}$ or overnight at $4{ }^{\circ} \mathrm{C}$. After incubation, the particles were washed once with PBS, then centrifuged $3 \mathrm{~min}$ at $3000 \mathrm{rpm}$ on a desktop microcentrifuge followed by two washes with Dulbecco's Modified Eagle's Medium (DMEM) supplemented with $10 \%$ heat-inactivated fetal calf serum, 100 units $/ \mathrm{mL}$ penicillin $\mathrm{G}, 100 \mathrm{ug} / \mathrm{mL}$ streptomycin sulfate, and $0.29 \mathrm{mg} / \mathrm{mL}$ of L-glutamine (Gibco-Invitrogen), the complete DMEM. The nanoparticles were resuspended in $100 \mu \mathrm{L}$ of complete DMEM and added to each well of 6-well plates containing $1 \mathrm{~mL}$ of complete DMEM. After $4 \mathrm{~h}$ of incubation at $37{ }^{\circ} \mathrm{C}$, the cells were washed 2 times with PBS and fixed with $4 \%$ paraformaldehyde in PBS ( $4{ }^{\circ} \mathrm{C}$ for $30 \mathrm{~min}$ ). The cells were washed again with PBS and the liquid was drained. A $200 \mu \mathrm{L}$ portion of antifade fluorescent mounting medium with DAPI was added in for staining the nuclei, and the cells were viewed under the fluorescent microscopy.

CD24 Staining. The nanoparticle-treated cells were fixed with 4\% PFA/PBS in 6-well plates and harvested by trypsinisation. The cells were washed once in PBS and resuspended in $200 \mu \mathrm{L}$ CD24 staining buffer and incubated for $1 \mathrm{~h}$ at room temperature. The staining buffer contains $0.1 \%(w / v)$ BSA (bovine serum albumin) and $5 \mu \mathrm{L}$ monoclonal antihuman CD24 antibody-FITC (BD, Australia) in PBS. The cells were washed three times with PBS and mounted onto slide by Cytospin 4 (Thermo Shandon). The cells were viewed using a confocal microscopy.

Quenching Oligo-DNA-Cy3 with DNase I. The nanoparticle treated cells were directly harvested by trypsination followed by one wash in PBS. The cells were fixed with $2 \%$ PFA/PBS at $4^{\circ} \mathrm{C}$ for $2 \mathrm{~h}$. The fixed cells were then divided into two halves. One half was for direct FACS analysis and the other half for DNase I treatment. For this treatment the cells were washed once in PBS, and the cell pellet was resuspended in $500 \mathrm{uL}$ treatment solution, which contains $1 \mathrm{mM} \mathrm{CaCls}, 0.5 \mathrm{mM} \mathrm{MgCl}, 0.1$ (w/v) BSA, and 120 Units of DNase I (Sigma, Australia) in PBS. After 30 min incubation at room temperature, the cells were washed for 3 times with PBS and resuspended in 2\% PFA/PBS for FACS analysis using BD LSR II analyzer (BD, Australia) and the results were analyzed using software FlowJo
Cytotoxicity of the Particles. The cervical cancer cell line SiHa was used for cytotoxicity test as it grows slower than HeLa cells. The cells were seeded in 96-well plates at $1 \times 10^{4}$ cells/well for $24 \mathrm{~h}$ before the testing. The particles (LP-MSNs, LP-MSN-P, and LP-MSN-A) were diluted in 2-fold series in the complete DMEM medium such as $1: 20,1: 40,1: 80$, and so on, and $100 \mu \mathrm{L}$ of each dilution was added to the cells. After $24 \mathrm{~h}$ of incubation at $37^{\circ} \mathrm{C}$, the treatment was stopped by washing the cells three times with fresh medium. The cells were cultured for another $24 \mathrm{~h}$ and the cytotoxicity was measured using Cell-Titer Glo method (Cell viability Luminescent Assay Kit, CellTiter-Glo, Promega) according to the instruction of the manufacturer .

Biological Function Assay for Delivering Functional siRNA. To examine whether the particles (LP-MSN-P and LP-MSN-A) can deliver functional molecules to cells for therapy, we chose siRNAs against Mirk and PLK1 genes. S10-siRNA which is effective against human papillomavirus (HPV) type 16 E6 gene was used as control. There is no HPV in KHOS cells therefore it can be used as negative control. The cells were seeded at $8000-10000$ cells/ well in $100 \mu \mathrm{L}$ of complete DMEM medium in 96-well plate and culture for overnight before treatment. The siRNAs were absorbed to particles as described above for 21-nucleotide oligo DNA and were added to the cells. The cells were treated for $48 \mathrm{~h}$ and the silencing effect or cell viability was determined by CellTiter-Glo assay.

Characterization. TEM images were obtained by a JEOL 2100 electron microscope with an acceleration voltage $200 \mathrm{kV}$. SEM images were recorded on a JEOL 6300 microscope operated at 5-10 kV. Nitrogen sorption isotherms of the samples were obtained at $-196{ }^{\circ} \mathrm{C}(77 \mathrm{~K})$ using a Quantachrome's Quadrasorb SI analyzer. Before the measurements, the samples were degassed overnight in vacuum. The BrumauerEmmett-Teller (BET) surface area was calculated using experimental points at a relative pressure of $P / P_{0}=0.05-0.25$. The total pore volume was calculated from the $\mathrm{N}_{2}$ amount adsorbed at the highest $P / P_{0}\left(P / P_{0}=0.99\right)$. The pore size distribution was calculated by the Broekhoff-de Boer (BdB) method using a spherical model. The cavity pore size and entrance pore size are determined from the adsorption and desorption branches, respectively, using the BdB method. XPS spectra were recorded on a Kratos Axis Ultra with a monochromatic Al K $\alpha$ X-ray source. Each spectrum was recorded at a survey scan from 0 to $1200 \mathrm{eV}$ with a dwell time of $100 \mathrm{~ms}$, pass energy of $160 \mathrm{eV}$ at steps of $1 \mathrm{eV}$ with 1 sweep. A high resolution scan was conducted at a lower pass energy $(20 \mathrm{eV})$, higher sweep and dwell time at $250 \mathrm{~ms}$. C1s with a binding energy of $285 \mathrm{eV}$ was used as the reference. The atomic ratio of LP-MSNs and their functionalized forms (LP-MSN-E, LP-MSN-P, and LP-MSN-A) were determined from XPS spectra. Solid state magic-angle spinning (MAS) ${ }^{13} \mathrm{C}$ nuclear magnetic resonance (NMR) measurements were performed with a Bruker MSL-300 spectrometer operating at a frequency of $75.482 \mathrm{MHz}$ for ${ }^{13} \mathrm{C}$. The spectrometer was equipped with a 4-mm double air bearing, magic angle spinning probe for MAS experiments. The proton $90^{\circ}$ pulse time used in the CPMAS method was $5.5 \mu \mathrm{s}$, the acquisition time was $45 \mathrm{~ms}$, cross-polarization time was $2 \mathrm{~ms}$, and the relaxation delay was $3 \mathrm{~s}$. The spectrum width was $50 \mathrm{kHz}$, and 4000 data points were collected over 2000 scans. The chemical shift of the ${ }^{13} \mathrm{C}$ spectrum was referenced to the resonance of adamantine at $38.23 \mathrm{ppm}$. All samples were equilibrated at room temperature $\left(22^{\circ} \mathrm{C}\right)$. Zeta potential measurements and Dynamic Light Scattering (DLS) were carried out by using a Zeta Sizer Nano-SZ from Malvern Instrument. LP-MSNs were suspended in PBS buffer $(\mathrm{pH} 7.4)$ at a concentration of $0.5 \mathrm{mg} / \mathrm{mL}$. The samples were mixed well by sonication and vortex before analysis. Fourier transformed infrared spectra were measured on a Nicolet 6700 FTIR; 32 scans were collected at a resolution of $4 \mathrm{~cm}^{-1}$. TGA/DSC 1 (Mettler-Toledo AG) was used for TGA at a heating rate of $2{ }^{\circ} \mathrm{C} / \mathrm{min}$ under a nitrogen flow of $20 \mathrm{~mL} / \mathrm{min}$. Small-angle X-ray scattering (SAXS) was performed using an Anton-Parr SAXSess small-angle $X$-ray scattering system ( $\mathrm{Cu} \mathrm{K} \alpha$ radiation, $40 \mathrm{kV}, 35 \mathrm{~mA}$ ).

Conflict of Interest: The authors declare no competing financial interest. 
Acknowledgment. This work was financially supported by the Australian Research Council (ARC) through the Linkage Project program (LP0882681) and the Discovery Project program (DP1095861, DP0987969). B. Wood from The Brisbane Surface Analysis Facility is acknowledged for support in XPS analysis and E. Strounina from Centre for Advanced Imaging for NMR analysis and also J. Fitzpatrick for technical help in confocal microscopy. S. B. Hartono gratefully acknowledges the UQIRTA and UQRS scholarship from The University of Queensland. L. He acknowledges support in the form of a Research Fellowship from the Australian Institute of Nuclear Science and Technology (AINSE Ltd). F. Kleitz acknowledges financial support from the Natural Sciences and Engineering Research Council of Canada (NSERC) and the AER program of Université Laval, Canada. The authors are grateful for additional financial support from the Challenge Project Initiatives from Australian Institute for Bioengineering and Nanotechnology.

Supporting Information Available: SAXS of LP-MSNs; nitrogen sorption and related pore size distribution, TGA, FTIR analysis, and particle size distribution of LP-MSNs, LP-MSN-P, and LP-MSN-A. This material is available free of charge via the Internet at http://pubs.acs.org.

\section{REFERENCES AND NOTES}

1. Ozpolat, B.; Sood, A. K.; Lopez-Berestein, G. Nanomedicine Based Approaches for the Delivery of SiRNA in Cancer. J. Intern. Med. 2009, 267, 44-53.

2. Sibley, C. R.; Seow, Y.; Wood, M. J. A. Novel RNA-Based Strategies for Therapeutic Gene Silencing. Mol. Ther. 2010, 18, 466-476.

3. Reischl, D.; Zimmer, A. Drug Delivery of SiRNA Therapeutics: Potentials and Limits of Nanosystems. Nanomedicine 2009, 5, 8-20.

4. Pathak, A.; Patnaik, S.; Gupta, K. C. Recent Trends in Nonviral Vector-Mediated Gene Delivery. Biotechnol. J. 2009, 4, 1559-1572.

5. Rosenholm, J. M.; Peuhu, E.; Bate-Eya, L. T.; Erikson, J. E.; Sahlgren, C.; Linden, M. Cancer-Cell-Specific Induction of Apoptosis Using Mesoporous Silica Nanoparticles as DrugDelivery Vectors. Small 2010, 6, 1234-1241.

6. Mamaeva, V.; Rosenholm, J. M.; Bate-Eya, L. T.; Bergman, L.; Peuhu, E.; Duchanoy, A.; Fortelius, L. E.; Landor, S.; Toivola, D. M.; Linden, M.; et al. Mesoporous Silica Nanoparticles as Drug Delivery Systems for Targeted Inhibition of Notch Signaling in Cancer. Mol. Ther. 2011, 19, 1538-1546.

7. Xia, T.; Kovochich, M.; Liong, M.; Meng, H.; Kabehie, S.; George, S.; Zink, J. I.; Nel, A. E. Polyethyleneimine Coating Enhances the Cellular Uptake of Mesoporous Silica Nanoparticles and Allows Safe Delivery of SiRNA and DNA Constructs. ACS Nano 2009, 3, 3273-3286.

8. Vallet-Regi, M.; Balas, F.; Arcos, D. Mesoporous Materials for Drug Delivery. Angew. Chem., Int. Ed. 2007, 46, 7548-7558.

9. Hartono, S. B.; Qiao, S. Z.; Liu, J.; Jack, K.; Ladewig, B. P.; Hao, Z.; Lu, G. Q. M. Functionalized Mesoporous Silica with Very Large Pores for Cellulase Immobilization. J. Phys. Chem. C 2010, 114, 8353-8362.

10. Kneuer, C.; Sameti, M.; Haltner, E. G.; Schiestel, T.; Schirra, H.; Schmidt, H.; Lehr, C. M. Silica Nanoparticles Modified with Aminosilanes as Carriers for Plasmid DNA. Int. J. Pharm. 2000, 196, 257-261.

11. Meng, H.; Liong, M.; Xia, T.; Li, Z.; Ji, Z.; Zink, J. I.; Nel, A. E. Engineered Design of Mesoporous Silica Nanoparticles to Deliver Doxorubicin and P-Glycoprotein SiRNA to Overcome Drug Resistance in a Cancer Cell Line. ACS Nano 2010, 4, 4539-4550.

12. Hom, C.; Lu, J.; Liong, M.; Luo, H.; Li, Z.; Zink, J. I.; Tamanoi, F. Mesoporous Silica Nanoparticles Facilitate Delivery of SiRNA to Shutdown Signaling Pathways in Mammalian Cells. Small 2010, 6, 1185-1190.

13. Li, X.; Zhang, J.; Gu, H. Adsorption and Desorption Behaviors of DNA with Magnetic Mesoporous Silica Nanoparticles. Langmuir 2011, 27, 6099-6106.
14. Solberg, S. M.; Landry, C. C. Adsorption of DNA into Mesoporous Silica. J. Phys. Chem. B 2006, 110, 1526115268.

15. Gao, F.; Botella, P.; Corma, A.; Blesa, J.; Dong, L. Monodispersed Mesoporous Silica Nanoparticles with Very Large Pores for Enhanced Adsorption and Release of DNA. J. Phys. Chem. B 2009, 113, 1796-1804.

16. Kim, M.-H.; Na, H.-K.; Kim, Y.-K.; Ryoo, S.-R.; Cho, H. S.; Lee, K. E.; Jeon, H.; Ryoo, R.; Min, D.-H. Facile Synthesis of Monodispersed Mesoporous Silica Nanoparticles with Ultralarge Pores and Their Application in Gene Delivery. ACS Nano 2011, 5, 3568-3576.

17. Tanaka, T.; Mangala, L. S.; Vivas-Mejia, P. E.; Nieves-Alicea, R.; Mann, A. P.; Mora, E.; Han, H.-D.; Shahzad, M. M. K.; Liu, X.; Ferrari, M.; et al. Sustained Small Interfering RNA Delivery by Mesoporous Silicon Particles. Cancer Res. 2010, 70, 3687-3696.

18. Moghimi, S. M.; Hunter, A. C.; Murray, J. C. Nanomedicine: Current Status and Future Prospects. FASEB J. 2005, 19, 311-330.

19. Bhattarai, S. R.; Muthuswamy, E.; Wani, A.; Brichacek, M.; Castaneda, A. L.; Brock, S. L.; Oupicky, D. Enhanced Gene and SiRNA Delivery by Polycation-Modified Mesoporous Silica Nanoparticles Loaded with Chloroquine. Pharm. Res. 2010, 27, 2556-2568.

20. Wolfert, M. A.; Dash, P. R.; Nazarova, O.; Oupicky, D.; Seymour, L. W.; Smart, S.; Strohalm, J.; Ulbrich, K. Polyelectrolyte Vectors for Gene Delivery: Influence of Cationic Polymer on Biophysical Properties of Complexes Formed with DNA. Bioconjugate Chem. 1999, 10, 993-1004.

21. Liu, G.; Molas, M.; Grossmann, G. A.; Pasumarthy, M.; Perales, J. C.; Cooper, M. J.; Hanson, R. W. Biological Properties of Poly-L-lysine-DNA Complexes Generated by Cooperative Binding of the Polycation. J. Biol. Chem. 2001, 276, 34379-34387.

22. Chen, A. M.; Zhang, M.; Wei, D.; Stueber, D.; Taratula, O.; Minko, T.; He, H. Co-delivery of Doxorubicin and BCL-2 SiRNA by Mesoporous Silica Nanoparticles Enhances the Efficacy of Chemotherapy in Multidrug-Resistant Cancer Cells. Small 2009, 5, 2673-2677.

23. Zhu, S.; Lu, H.; Xiang, J.; Tang, K.; Zhang, B.; Zhou, M.; Tan, C.; Li, G. A Novel Nonviral Nanoparticle Gene Vector: PolyL-lysine-Silica Nanoparticles. Chin. Sci. Bull. 2002, 47, 654-658.

24. Zhu, S.-G.; Xiang, J.-J.; Li, X.-L.; Shen, S.-R.; Lu, H.-b.; Zhou, J.; Xiong, W.; Zhang, B.-C.; Nie, X.-M.; Zhou, M.; Tang, K.; Li, G.-Y. Poly(L-lysine)-Modified Silica Nanoparticles for the Delivery of Antisense Oligonucleotides. Biotechnol. Appl. Biochem. 2004, 39, 179-187.

25. Li, Z.; Zhu, S.; Gan, K.; Zhang, Q.; Zeng, Z.; Zhou, Y.; Liu, H.; Xiong, W.; Li, X.; Li, G. Poly-L-lysine-Modified Silica Nanoparticles: A Potential Oral Gene Delivery System. J. Nanosci. Nanotechnol. 2005, 5, 1199-1203.

26. Lunn, J. D.; Shantz, D. F. Peptide Brush-Ordered Mesoporous Silica Nanocomposite Materials. Chem. Mater. 2009, 21, 3638-3648.

27. Kar, M.; Malvi, B.; Das, A.; Panneri, S.; Gupta, S. S. Synthesis and Characterization of Poly-L-lysine Grafted SBA-15 Using NCA Polymerization and Click Chemistry. J. Mater. Chem. 2011, 21, 6690-6697.

28. Yiu, H. H. P.; Niu, H.-j.; Biermans, E.; van Tendeloo, G.; Rosseinsky, M. J. Designed Multifunctional Nanocomposites for Biomedical Applications. Adv. Funct. Mater. 2010, 20, 1599-1609.

29. Fan, J.; Yu, C.; Lei, J.; Zhang, Q.; Li, T.; Tu, B.; Zhou, W.; Zhao, D. Low-Temperature Strategy to Synthesize Highly Ordered Mesoporous Silicas with Very Large Pores. J. Am. Chem. Soc. 2005, 127, 10794-10795.

30. Lukens, W. W., Jr.; Schmidt-Winkel, P.; Zhao, D.; Feng, J.; Stucky, G. D. Evaluating Pore Sizes in Mesoporous Materials: A Simplified Standard Adsorption Method and a Simplified Broekhoff-De Boer Method. Langmuir 1999, 15, 5403-5409.

31. Fan, J.; Yu, C.; Gao, F.; Lei, J.; Tian, B.; Wang, L.; Luo, Q.; Tu, B.; Zhou, W.; Zhao, D. Cubic Mesoporous Silica with Large 
Controllable Entrance Sizes and Advanced Adsorption Properties. Angew. Chem., Int. Ed. 2003, 42, 3146-3150.

32. Schacht, S.; Janicke, M.; Schuth, F. Modeling X-ray Patterns and TEM Images of MCM-41. Microporous Mesoporous Mater. 1998, 22, 485-493.

33. Pauwels, B.; Van Tendeloo, G.; Thoelen, C.; Van Rhijn, W.; Jacobs, P. A. Structure Determination of Spherical MCM-41 Particles. Adv. Mater. 2001, 13, 1317-1320.

34. Han, Y.; Ying, J. Y. Generalized Fluorocarbon-SurfactantMediated Synthesis of Nanoparticles with Various Mesoporous Structures. Angew. Chem., Int. Ed. 2005, 44, 288292.

35. Suteewong, T.; Sai, H.; Cohen, R.; Wang, S.-T.; Bradbury, M.; Baird, B.; Gruner, S. M.; Wiesner, U. Highly Aminated Mesoporous Silica Nanoparticles with Cubic Pore Structure. J. Am. Chem. Soc. 2011, 133, 172-175.

36. Roy, I.; Ohulchanskyy, T. Y.; Bharali, D. J.; Pudavar, H. E.; Mistretta, R. A.; Kaur, N.; Prasad, P. N. Optical Tracking of Organically Modified Silica Nanoparticles as DNA Carriers: A Nonviral, Nanomedicine Approach for Gene Delivery. Proc. Natl. Acad. Sci. U.S.A. 2005, 102, 279-284.

37. Sayari, A.; Hamoudi, S. Periodic Mesoporous Silica-Based Organic-Inorganic Nanocomposite Materials. Chem. Mater. 2001, 13, 3151-3168.

38. Sales, J. A. A.; Prado, A. G. S.; Airoldi, C. The Incorporation of Propane-1,3-Diamine into Silica Gel through Surface Epoxide Groups by Homogeneous and Heterogeneous Routes. Polyhedron 2002, 21, 2647-2651.

39. Luten, J.; van Nostrum, C. F.; De Smedt, S. C.; Hennink, W. E. Biodegradable Polymers as Non-viral Carriers for Plasmid DNA Delivery. J. Controlled Release 2008, 126, 97-110.

40. Symonds, P.; Murray, J. C.; Hunter, A. C.; Debska, G.; Szewczyk, A.; Moghimi, S. M. Low and High Molecular Weight Poly(L-lysine)S/poly(L-lysine)-DNA Complexes Initiate Mitochondrial-Mediated Apoptosis Differently. FEBS Lett. 2005, 579, 6191-6198.

41. Wahab, M. A.; Imae, I.; Kawakami, Y.; Ha, C.-S. Periodic Mesoporous Organosilica Materials Incorporating Various Organic Functional Groups: Synthesis, Structural Characterization, and Morphology. Chem. Mater. 2005, 17, 21652174.

42. Mirau, P. A.; Serres, J. L.; Lyons, M. The Structure and Dynamics of Poly(L-lysine) in Templated Silica Nanocomposites. Chem. Mater. 2008, 20, 2218-2223.

43. Fernandez, V. L.; Reimer, J. A.; Denn, M. M. Magnetic Resonance Studies of Polypeptides Adsorbed on Silica and Hydroxyapatite Surfaces. J. Am. Chem. Soc. 1992, 114, 9634-42.

44. Zhang, Q.; Huang, R. F.; Guo, L.-H. One-Step and HighDensity Protein Immobilization on Epoxysilane-Modified Silica Nanoparticles. Chin. Sci. Bull. 2009, 54, 2620-2626.

45. Kar, M.; Vijayakumar, P. S.; Prasad, B. L. V.; Sen Gupta, S. Synthesis and Characterization of Poly-L-lysine-Grafted Silica Nanoparticles Synthesized via NCA Polymerization and Click Chemistry. Langmuir 2010, 26, 5772-5781.

46. Jones, N. A.; Hill, I. R. C.; Stolnik, S.; Bignotti, F.; Davis, S. S.; Garnett, M. C. Polymer Chemical Structure Is a Key Determinant of Physicochemical and Colloidal Properties of Polymer-DNA Complexes for Gene Delivery. Biochim. Biophys. Acta, Gene Struct. Expression 2000, 1517, 1-18.

47. Leng, M.; Felsenfeld, G. The Preferential Interactions of Polylysine and Polyarginine with Specific Base Sequences in DNA. Proc. Natl. Acad. Sci. U.S.A. 1966, 56, 1325-32.

48. Shapiro, J. T.; Leng, M.; Felsenfeld, G. Deoxyribonucleic Acid-Polylysine Complexes. Structure and Nucleotide Specificity. Biochemistry 1969, 8, 3219-32.

49. Consolandi, C.; Castiglioni, B.; Bordoni, R.; Busti, E.; Battaglia, C.; Bernardi, L. R.; De Bellis, G. Two Efficient Polymeric Chemical Platforms for Oligonucleotide Microarray Preparation. Nucleosides, Nucleotides Nucleic Acids 2002, 21, 561-580.

50. Beier, M.; Hoheisel, J. D. Versatile Derivatization of Solid Support Media for Covalent Bonding on DNA-Microchips. Nucleic Acids Res. 1999, 27, 1970-1977.
51. Martin, A. L.; Bernas, L. M.; Rutt, B. K.; Foster, P. J.; Gillies, E. R. Enhanced Cell Uptake of Superparamagnetic Iron Oxide Nanoparticles Functionalized with Dendritic Guanidines. Bioconjugate Chem. 2008, 19, 2375-2384.

52. Xia, T.; Kovochich, M.; Liong, M.; Zink, J. I.; Nel, A. E. Cationic Polystyrene Nanosphere Toxicity Depends on Cell-Specific Endocytic and Mitochondrial Injury Pathways. ACS Nano 2008, 2, 85-96.

53. Gao, J.; Zheng, Z.; Rawal, B.; Schell, M. J.; Bepler, G.; Haura, E. B. Mirk/Dyrk1b, a Novel Therapeutic Target, Mediates Cell Survival in Non-small Cell Lung Cancer Cells. Cancer Biol. Ther. 2009, 8, 1671-1679.

54. Duan, Z.; Ji, D.; Weinstein, E. J.; Liu, X.; Susa, M.; Choy, E.; Yang, C.; Mankin, H.; Hornicek, F. J. Lentiviral ShRNA Screen of Human Kinases Identifies Plk1 as a Potential Therapeutic Target for Osteosarcoma. Cancer Lett. (Shannon, Irel.) 2010, 293, 220-229.

55. Putral, L. N.; Bywater, M. J.; Gu, W.; Saunders, N. A.; Gabrielli, B. G.; Leggatt, G. R.; McMillan, N. A. J. RNA Interference against Human Papillomavirus Oncogenes in Cervical Cancer Cells Results in Increased Sensitivity to Cisplatin. Mol. Pharmacol. 2005, 68, 1311-1319.

56. Oh, Y.-K.; Park, T. G. SiRNA Delivery Systems for Cancer Treatment. Adv. Drug Delivery Rev. 2009, 61, 850-862.

57. Gad, A. E.; Silver, B. L.; Eytan, G. D. Polycation-Induced Fusion of Negatively-Charged Vesicles. Biochim. Biophys. Acta, Biomembr. 1982, 690, 124-32.

58. Wang, C. Y.; Huang, L. Polyhistidine Mediates an AcidDependent Fusion of Negatively Charged Liposomes. Biochemistry 1984, 23, 4409-16.

59. Schaffer, D. V.; Fidelman, N. A.; Dan, N.; Lauffenburger, D. A. Vector Unpacking as a Potential Barrier for ReceptorMediated Polyplex Gene Delivery. Biotechnol. Bioeng. 2000, 67, 598-606. 


\section{Supporting Information}

\section{Poly-L-lysine Functionalized Large Pore Cubic Mesostructured Silica Nanoparticles as Biocompatible Carriers for Gene Delivery}

Sandy B. Hartono ${ }^{1 \dagger}$, Wenyi $\mathrm{Gu}^{1 \dagger}$, Freddy Kleitz ${ }^{3}$, Jian Liu ${ }^{1}$, Lizhong He ${ }^{4}$, Anton P.J. Middelberg ${ }^{4}$, Chengzhong $\mathrm{Yu}^{1}$ *, Gao Qing (Max) $\mathrm{Lu}^{1}$ and Shi Zhang Qiao ${ }^{1,2} *$

${ }^{1}$ ARC Centre of Excellence for Functional Nanomaterials, Australian Institute for Bioengineering and Nanotechnology, The University of Queensland, QLD 4072, Australia

${ }^{2}$ School of Chemical Engineering, The University of Adelaide, SA5005, Australia

${ }^{3}$ Department of Chemistry and Centre de recherche sur les matériaux avancés (CERMA), Université Laval, Quebec City, GIV 0A6, QC, Canada

${ }^{4}$ Centre for Biomolecular Engineering, Australian Institute for Bioengineering and Nanotechnology, The University of Queensland, QLD 4072, Australia

* Address correspondence to s.qiao@uq.edu.au (S.Z. Qiao), c.yu@uq.edu.au (C. Yu), 1.he@uq.edu.au (L.He)

${ }^{\dagger}$ These authors contributed equally to this work 

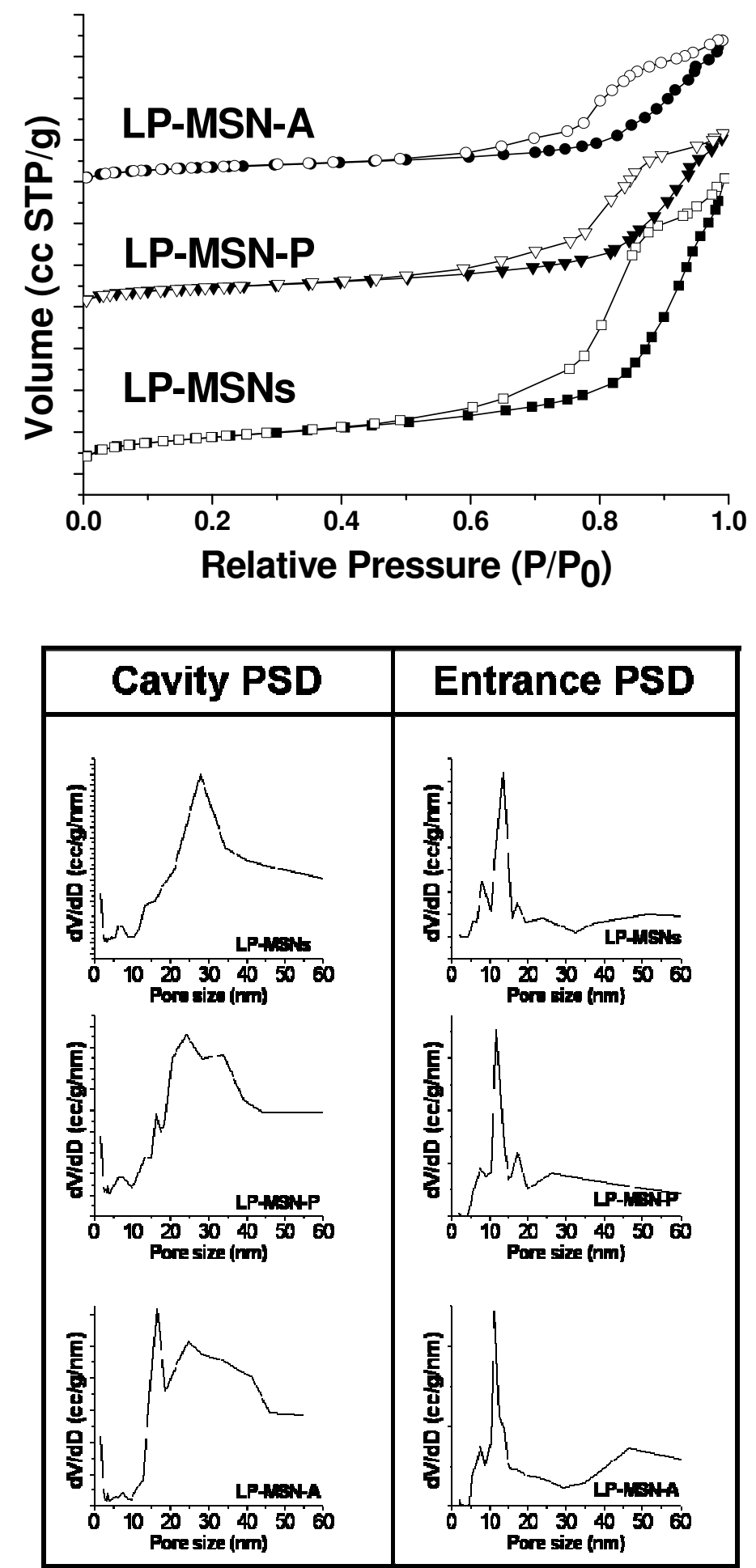

Figure S1. Nitrogen sorption isotherms (top) and pore size distributions (PSD) (bottom) of LP-MSNs, LP-MSN-P and LP-MSN-A. For improved clarity, isotherms LP-MSN-P and LP-MSN-A are shifted vertically by 400 and $700 \mathrm{cc} \mathrm{STP/g}$ 


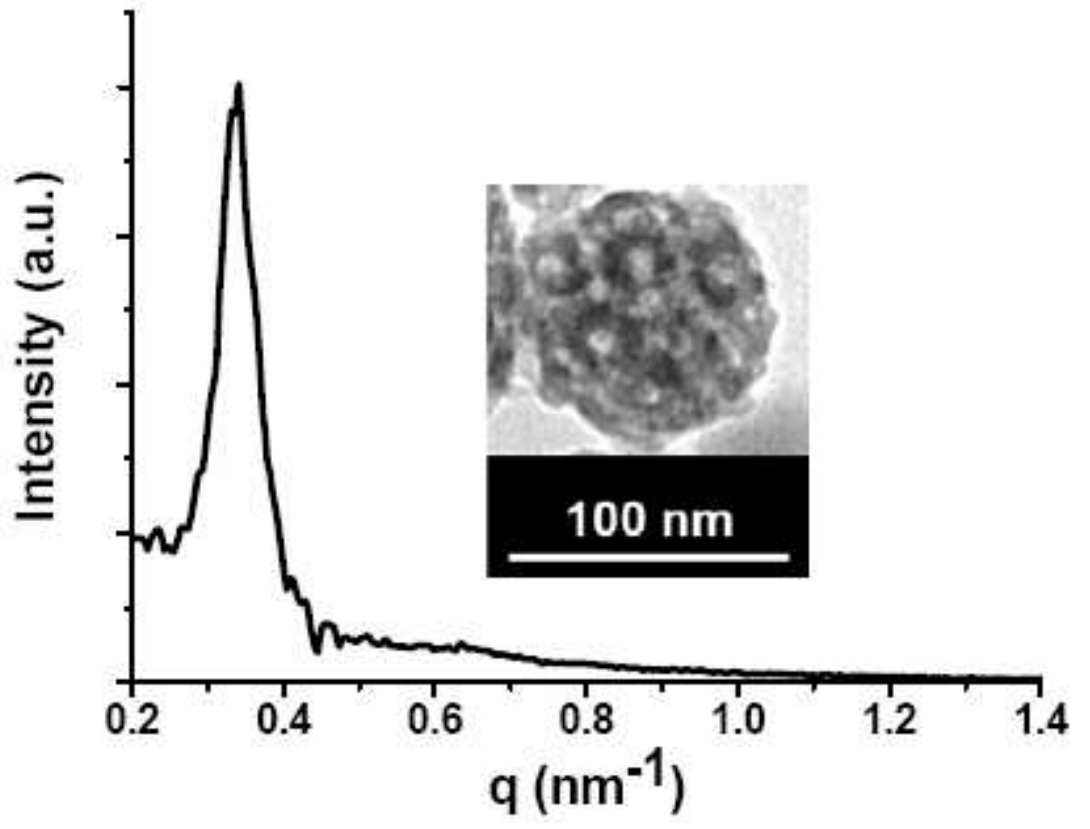

Figure S2. SAXS pattern of LP-MSNs. Inset is a TEM image showing the cubic structure of LP-MSNs.

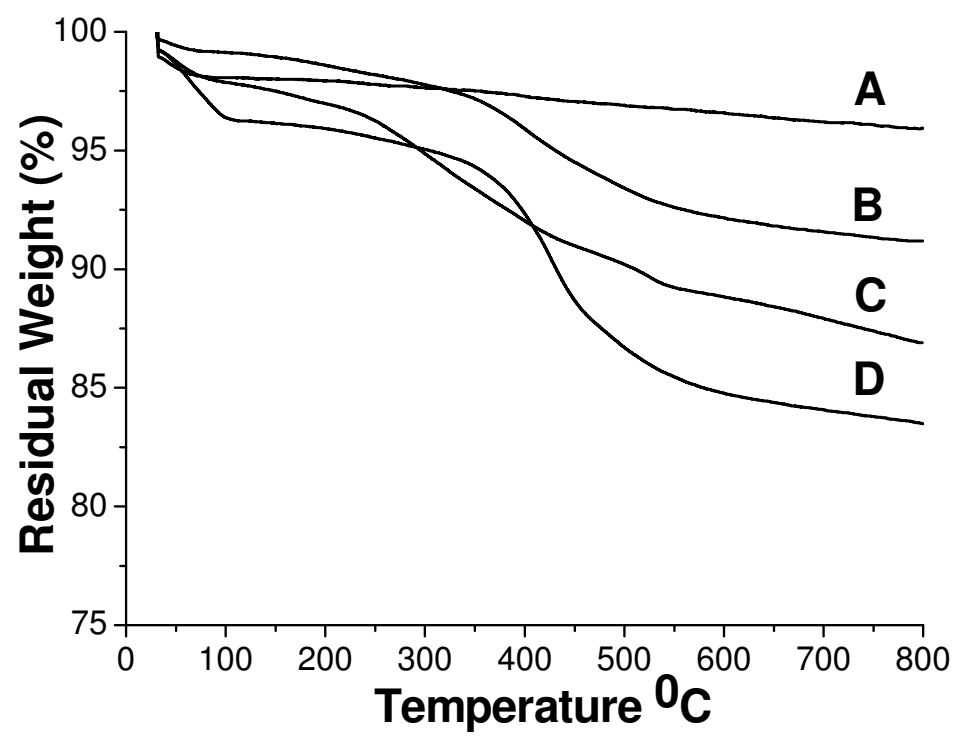

Figure S3. TGA analyses of (A) LP-MSNs, (B) LP-MSN-E, (C) LP-MSN-P and (D) LP-MSN-A 

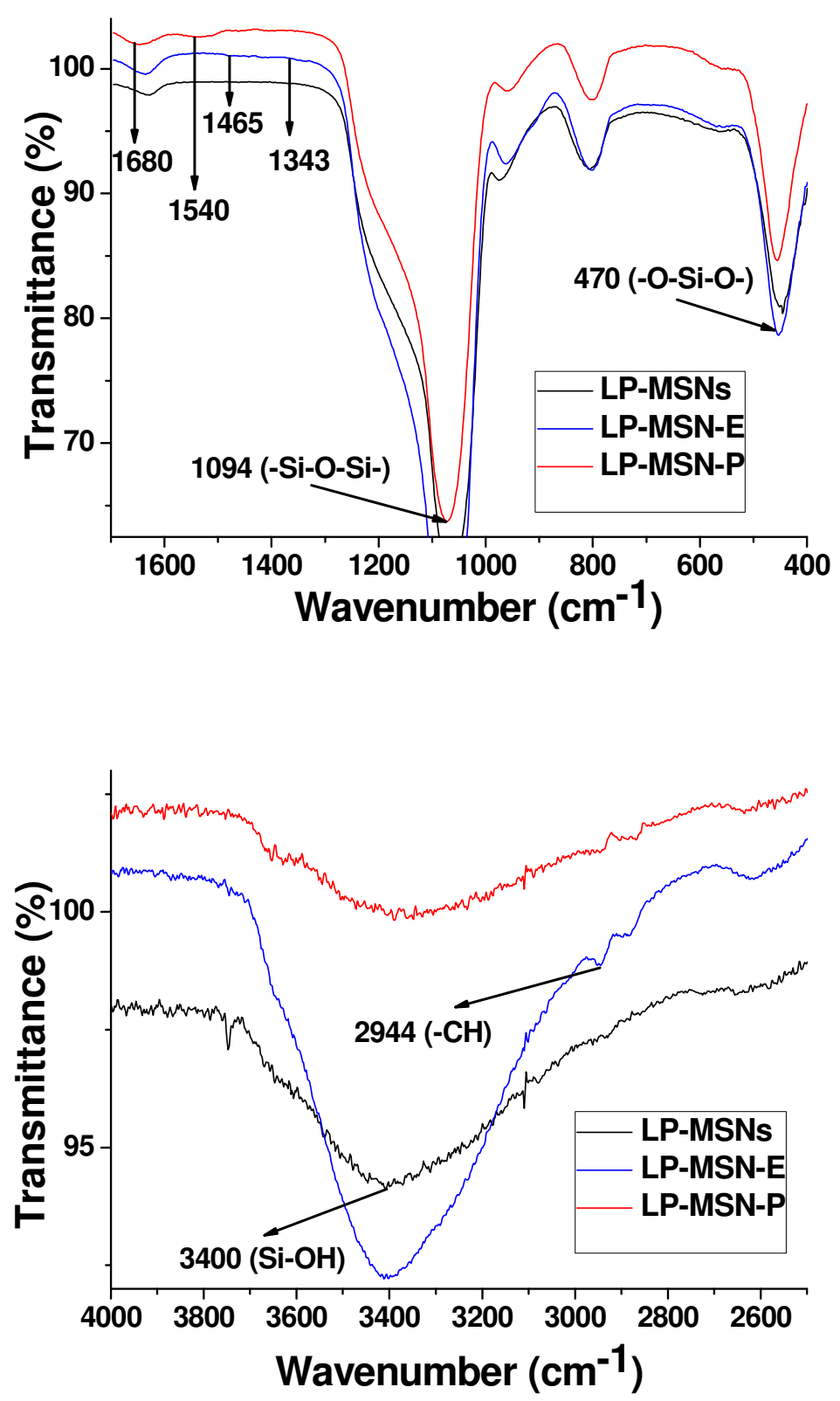

Figure S4. FTIR spectra of LP-MSNs, LP-MSN-E and LP-MSN-P. 

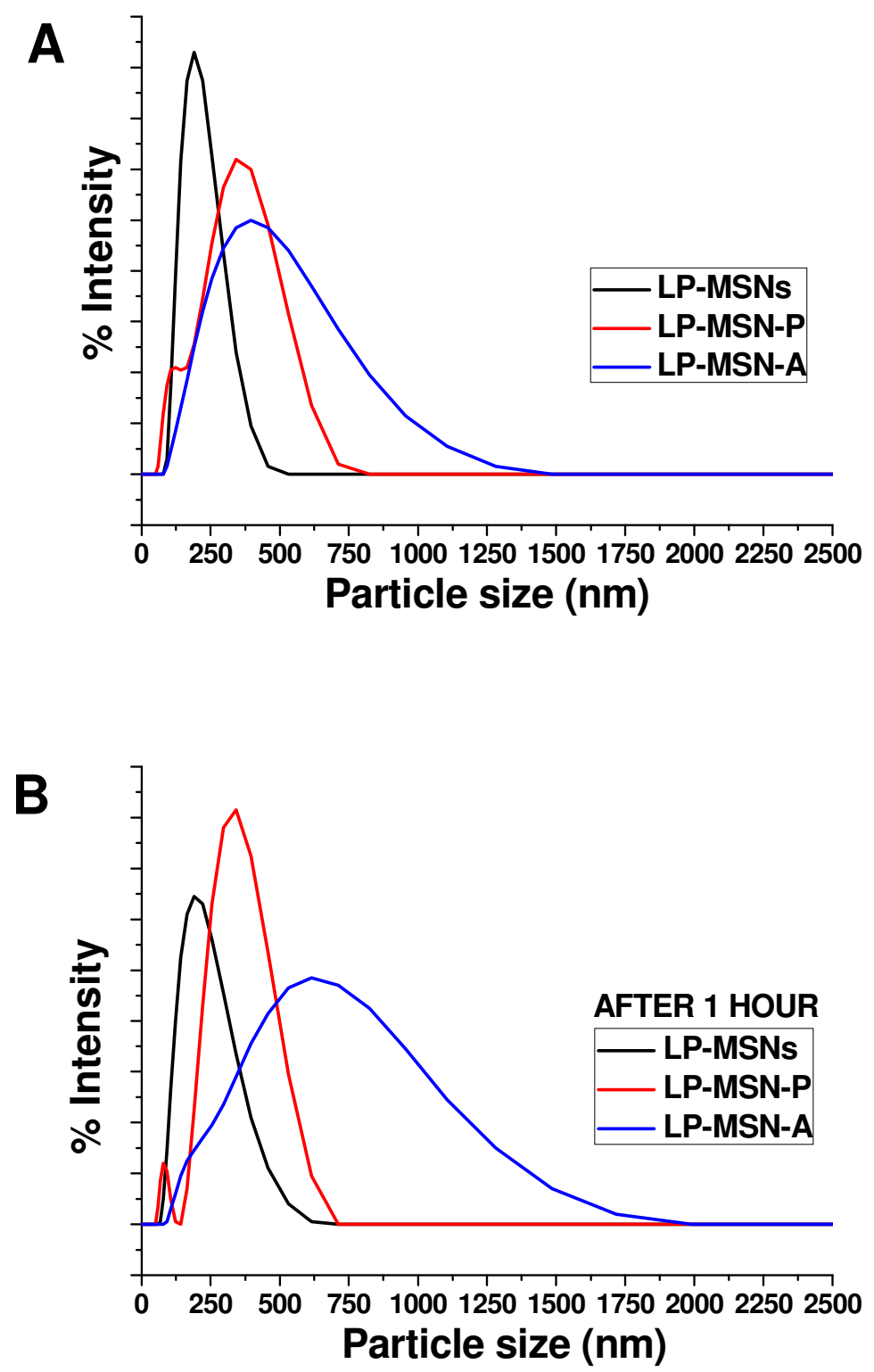

Figure S5. Nanoparticle size distributions obtained by DLS for LP-MSNs, LP-MSN-P and LP-MSN-A (A) after mixing and (B) one hour after mixing.

We measured the hydrodynamic size of LP-MSNs after mixing and one hour after mixing, to determine the silica stability in PBS buffer. The stability test indicated that LP-MSN-P were more stable compared to LP-MSN-A.

The aggregation tendency of LP-MSN-A can be seen directly even right after mixing (Figure S5 A). The mean hydrodynamic size of LP-MSNs, LP-MSN-P and LP-MSN-A were $205 \mathrm{~nm}, 334 \mathrm{~nm}$ and 419 nm, 
respectively. After one hour mixing, there were no substantial changes in hydrodynamic size for LPMSNs and LP-MSN-P. The particle size of LP-MSNs was around 216, while LP-MSN-P's size was around 340. In contrary, pronounced aggregation of the LP-MSN-A particles was observed and their mean particle size increased quite significantly to $587 \mathrm{~nm}$.

Previous research indicated that amine-silane functionalized silica tended to aggregate. ${ }^{1,2}$ The main reason for the amine's aggregation was attributed to the effect of "back bonding" where amine moieties interacted with the negatively charged of silanol group on the silica surface. ${ }^{1}$ However, in of the case of the LP-MSN-P, we believe that the 3-D elongated structures of PLL make amine moieties away from the silanol groups (only the amine moieties that lie very close to the silanol groups undergo the back bonding) and thus can maintain proper electrostatic repulsion. As a result, the aggregation of LP-MSN-P can be minimized and the particle dispersability can be maintained.

1. Bagwe, R. P.; Hilliard, L. R.; Tan, W. Surface Modification of Silica Nanoparticles to Reduce Aggregation and Nonspecific Binding. Langmuir 2006, 22, 4357-4362.

2. Kim, M.-H.; Na, H.-K.; Kim, Y.-K.; Ryoo, S.-R.; Cho, H. S.; Lee, K. E.; Jeon, H.; Ryoo, R.; Min, D.-H. Facile Synthesis of Monodispersed Mesoporous Silica Nanoparticles with Ultralarge Pores and Their Application in Gene Delivery. ACS Nano 2011, 5, 3568-3576. 